\title{
JOSÉ SÁNCHEZ SOMOANO: UN PROFESOR DE EDUCACIÓN FÍSICA ESCOLAR ENTRE MADRID Y MÉXICO (1887-1913)
}

\author{
José Sánchez Somoano: A school physical education teacher \\ between Madrid and Mexico (1887-1913)
}

\section{Xavier Torrebadella-Flix*}

Fecha de recepción: 14/07/2017 • Fecha de aceptación: 17/12/2017

Resumen. En la convulsa encrucijada política y nacionalista del siglo XIX y principios del siglo $\mathrm{xx}$, la configuración de los diferentes sistemas gimnásticos y de educación física representó, tanto en Europa como en América, un espacio de singulares y debatidas controversias técnicas e ideológicas. En esta coyuntura, algunos profesionales de la gimnástica probaron suerte fuera de sus países y, a la vez que exportaron conocimientos de los diferentes métodos gimnásticos, también trataron de congeniar aspiraciones de progreso y de modernidad en los países de acogida. Uno de estos profesionales fue José Sánchez y González de Somoano, profesor de gimnástica español que mantuvo una estrecha vinculación profesional con México, durante la segunda presidencia del general Porfirio Díaz. Su labor como fundador y director del gimnasio de la Escuela Normal de Profesores de México, entre 1887 y 1889, hacen que su figura, todavía inédita en la historia de la educación, sea recuperada como objeto de estudio de este trabajo a partir de una reveladora biografía y el estudio bibliográfico de algunas de sus obras más emblemáticas. El análisis crítico de estas obras, en el contexto histórico de la propia materia, permite establecer las analogías y las diferencias en el desarrollo y la conceptualización de la educación física escolar entre España y México. Asimismo, la información presentada es significativamente representativa para al conocimiento social y cultural del momento histórico y la relación transoceánica que existió entre ambos países.

Palabras clave: Historia de la educación latinoamericana; Educación física; Gimnasia; Educación militar; Escuela Normal de Profesores de México

\footnotetext{
* Universidad Autónoma de Barcelona. Facultad de Ciencias de la Educación. Campus de la UAB Edificio G6, despacho 168. 08193 Bellaterra (Cerdanyola del Vallès). España. Franciscoxavier.torrebadella@uab.cat
}

Cómo citar este artículo: Torrebadella-Flix, Xavier. «José Sánchez Somoano: Un profesor de Educación Física Escolar entre Madrid y México (1887-1913)». Historia y Memoria de la Educación 8 (2018): 549-596. 
Abstract. At the tumultuous political and nationalist crossroads of the late nineteenth and early twentieth centuries, the formation of the different systems of gymnastics and physical education in both Europe and America represented an area of remarkable and highly-debated technical and ideological controversies. In the circumstances of that time, some professional gymnasts tried their luck in other countries and in doing so exported knowledge of the different gymnastic methods, and also tried to move closer to aspirations of progress and modernity in the host countries. One of these professionals was José Sánchez y González de Somoano, a Spanish gymnastics teacher who had a close professional link to Mexico during the second presidency of General Porfirio Díaz. His work as founder and director of the gymnasium at the teacher training college, the Escuela Normal de Profesores de México, from 1887 to 1889, has meant that his prominence, unmentioned until now in the history of education, has been restored as an object of study in this article, through a revealing biography and bibliographical research on some of his most iconic works. A critical analysis of these works, within the historical context of his work, enables us to address the analogies and differences in the development and conceptualisation of physical education in Spain and Mexico . Furthermore, , the information presented is significantly representative, providing a glimpse of the social and cultural context of the time as well as the transcontinental relationship that existed between the two countries.

Key words: History of Latin American education; Physical education; Gymnastics; Military education; Escuela Normal de Profesores de México

\section{INTRODUCCIÓN}

A partir de la Restauración borbónica se inició en el sistema educativo español un período en el que se intensificaron los discursos propagandísticos de aquellos profesionales de la gimnástica que han sido considerados los «apóstoles de la educación física», cuyo principal objetivo perseguía el oficializar la educación física en la primera y segunda enseñanza. ${ }^{1}$ Entre estos representantes se destacó la figura de José Sánchez y González de Somoano (Arriondas, 1850 - México, 1913), profesor de gimnástica (educación física) que ejerció su labor entre España y la República de México (Estados Unidos de México).

\footnotetext{
${ }^{1}$ Xavier Torrebadella, «Los apóstoles de la educación física. Trece semblanzas profesionales en la educación física española contemporánea», Revista Española de Educación Física 406 (2014): 57-76.
} 
En José Sánchez y González de Somoano (a partir de ahora José Sánchez) vamos a centrar el objeto de estudio de esta investigación, la cual pretende, además de rescatar para la memoria de la educación la figura de este personaje, dar a conocer la influencia que ejerció entre España y la República de México en la esfera de la institucionalización de la educación física escolar de ambos países.

El marco histórico viene fijado por el periodo de vida de este singular gimnasiarca, autor de una significativa obra en torno a la educación física escolar de finales del siglo XIX. Así el período de estudio comprende desde la primera mitad del siglo XIX, hasta 1913, año en el que José Sánchez muere en la ciudad de México. No obstante, principalmente nos ocupamos de centrar el estudio en momento histórico en el que se desenvuelve su aportación bibliográfica (1883-1895).

La estancia de José Sánchez en México y su colaboración con el Gobierno del General Porfirio Díaz (periodo porfiriato, 1876-1911) nos ha incitado a rescatar el protagonismo de este profesor, que además se autonombró profesor de gimnástica y fundador del Gimnasio Normal de la Escuela de Profesores de México. No obstante, este hecho suele pasar desapercibido en la historiografía de la educación física mexicana, en la que apenas se alude a la figura de este apóstol de la educación física, y solamente es el mismo José Sánchez quien trata del asunto en una reseña histórica de la gimnástica en México. ${ }^{2}$

La base del estudio ha seguido el método histórico (heurístico-hermenéutico), con lo cual proporcionamos una argumentación constructivista a partir de las fuentes primarias. Asimismo, hemos seguido el rastro de los datos biográficos de José Sánchez, principalmente a través de la búsqueda de noticias en la prensa española y mexicana, utilizado en este caso, la hemeroteca digital de la Biblioteca Nacional de España y la Hemeroteca Digital Nacional de México. No obstante, hemos partido de una contextualización alimentada por la revisión de las principales aportaciones en torno a la historia de la educación física de la República México y de España. Posteriormente, y tras el análisis de contenido de las obras publicadas por José Sánchez, condensamos una narrativa hermenéutica sobre el objeto de estudio.

\footnotetext{
${ }^{2}$ José Sánchez Somoano, Gimnástica escolar. Tomo I movimientos libres (Madrid: Manuel Minuesa de los Ríos, Impresor, ca. 1890), 19-27.
} 
Por otro lado, esta relación transoceánica, concede la oportunidad de establecer las analogías y diferencias del desarrollo y la significación de la educación física escolar entre ambos países (tabla 2).

\section{LOS COMIENZOS DE LA EDUCACIÓN FÍSICA ESCOLAR EN LA CIUDAD DE MÉXICO}

Se ha mencionado que la educación física en la ciudad de México arrancó con la llegada de Juan Turin (Jean Chadafaut Turin), alumno en Francia del gimnasiarca valenciano Francisco Amorós Ondeano, que montó el primer gimnasio de la ciudad (c/ Tacuba, 19) ${ }^{3}$ y que ha sido considerado como el introductor de la gimnástica en este país. ${ }^{4}$ Esto sucedía en el año 1846, época en la que se divulgaban argumentos sobre la importancia de la gimnástica en los tiempos modernos, ${ }^{5}$ y se emprendía su enseñanza en algunos de los colegios privados cuya dirección estuvo a cargo del propio Turin y de otros aventajados discípulos suyos. ${ }^{6}$ En estos colegios la educación física se atendía con ejercicios gimnásticos, esgrima, equitación y natación.

Un ejemplo fue el Gimnasio Mexicano, un prestigioso centro que en 1845 se estableció en la hacienda del Olivar del Conde, a media legua de Tacubaya, en el distrito centro de México. ${ }^{7}$ En este colegio se deseó educar con la máxima: nens sana in corpore sano, y por eso se pretendía incorporar al mejor profesorado posible traído de Europa, inclusive el de gimnástica. Así, entre los ramos de la educación se encontraba también la Gimnástica y sus diferentes manifestaciones en equitación, esgrima, natación, danza y otros varios ejercicios corporales (carreras, saltos, lu-

\footnotetext{
${ }^{3}$ "Gimnasio», Diario del Gobierno de la República Mexicana, 22 de noviembre de 1846, 4.

${ }^{4}$ «Teatro nacional. Los Luchadores», El Siglo Diez y Nueve (México), 13 de abril de 1849, 1.

${ }^{5}$ [Museo de las Familias], «La Gimnástica Moderna», El Siglo Diez y Nueve (México), 6 de diciembre de 1843, 2-3. Continua el 7 de diciembre, 3-4. [El Locomotor], «Veracruz, septiembre 16 de 1846. Gimnástica», Diario del Gobierno de la República, 6 de octubre de 1846, 2. Antonio De Iza de Zamacola, «De los Juegos Gimnicos», El Espectador de México, 28 de febrero de 1851, 299-303.

${ }^{6}$ Sánchez Somoano, Gimnástica escolar, 24-26. María José Garrido Asperó, Para sanar, fortalecer y embellecer los cuerpos. Historia de la gimnasia en la ciudad de México, 1824-1876 (México: Instituto Mora, 2016).

${ }^{7}$ Luis Napoleón Jaubert, «Remitido», Diario del Gobierno de la República Mexicana, 20 de noviembre de 1845, 323-324.
} 
chas, armas de fuego). ${ }^{8}$ El celo de la dirección del Gimnasio Mexicano no ponía reparos en estimar que,

apenas quedan por llenar ciertas funciones de las relativas a la gimnástica propiamente dicha, que tendrán a su cargo dos sujetos de mi satisfacción, entre tanto que puede hacerse venir algún profesor de Sevilla, en donde están ya planteados con muy feliz éxito otros establecimientos de este género, para que pueda presentaros al profesor que más convenga. ${ }^{9}$

Asimismo, algunos de los alumnos de Turin se establecieron por cuenta propia sin la debida preparación, con lo que las desgracias no tardaron en llegar. El mismo Turin tuvo que proteger su acreditada reputación al verse en vuelto en un desafortunado suceso acaecido a uno de sus discípulos. ${ }^{10}$

Turin también fue el introductor de la gimnástica en el Ejército y, como es lógico, echó mano del modelo militar francés, cuyo método se fundamentaba en la gimnástica de Francisco Amorós. Es, por lo tanto, el ejército el primero que publicó una reglamentación para uso de esta enseñanza, ${ }^{11}$ del mismo modo que años más tarde sucedió en España, cuyos reglamentos de enseñanza gimnástica son prácticamente calcados, puesto que ambos fueron una traducción del reglamento francés. ${ }^{12}$

Así, la gimnástica adquirió una orientación militar, sistematizada por el método de Amorós, con lo cual, en el ámbito escolar se fijaba mucho en el dispositivo disciplinar y en el endurecimiento a través de los ejercicios de fuerza.

\footnotetext{
${ }^{8}$ Luis Napoleón Jaubert, «Prospecto del gimnasio mexicano o nuevo establecimiento de educación moral, física e intelectual», Diario del Gobierno de la República Mexicana, 20 de octubre de 1843, 201-203.

${ }^{9}$ Luis Napoleón Jaubert, «Remitido. Concluye el artículo», Diario del Gobierno de la República Mexicana, 21 de noviembre de 1845, 327-328.

${ }^{10}$ «Un hijo de la Sra. Francesconi ha muerto haciendo ejercicios gimnásticos bajo la dirección de un individuo que no era profesor [...] la desgracia sucedida exige de la más eficaz vigilancia en las escuelas gimnásticas, para que no se conviertan en lugares de inminente peligro para los niños». Jean Turin, «Desgracia», El Siglo Diez y Nueve, México, 5 de diciembre de 1849, 4.

${ }^{11}$ Ministerio de Guerra y Marina, Decreto de Instrucción para la enseñanza de la gimnástica en los cuerpos del ejército y guardia y guardia nacional (México: Imprenta de Vicente G. Torres, 1850).

${ }^{12}$ José María Aparici, Instrucción para la enseñanza de la gimnástica en los cuerpos y establecimientos militares (Madrid: Rivadeneyra, Madrid, 1852).
} 
Como veremos, algunos de los alumnos más aventajados de Turin, como Feliciano Chavarria o Joaquín Noreña, se dedicaron a la profesión gimnástica abriendo gimnasios particulares, pero también impartiendo la enseñanza en los colegios nacionales y privados de México. Con lo cual, la gimnástica se hacía un hueco en la educación moderna, tal y como ya se estaba haciendo en otros avanzados países de Europa. Ello impulsó que la normativa de Instrucción Pública de 15 de abril de 1861 tuviera en consideración la confección de reglamentos para incorporar en todas las escuelas los ejercicios gimnásticos y la esgrima. ${ }^{13}$ Sin embargo, aunque esta iniciativa no satisfacía las expectativas deseadas para atender debidamente la educación física escolar, al quedar la decisión al antojo de la dirección de los centros educativos, en algunos colegios nacionales y en los colegios privados en los cuales se formaban las elites del país, sí se atendió la enseñanza de la gimnástica.

Como comprobamos, hacia mediados del siglo XIX, en algunos de los Estados de México la gimnasia también fue justificada para atender las necesidades educativas. Estados como el de Nuevo León o el de Veracruz emprendieron iniciativas al respecto, entrando así a formar parte del desarrollo de una educación moderna y de las «naciones civilizadas»:

Gobierno del Estado de Nuevo-León.-En las naciones civilizadas y en la capital de la nuestra se han establecido academias de gimnasia donde la juventud ejercita su fuerza física, por cuyo medio se desarrolla ésta en bien de la salud corporal y de la fuerza intelectual, que también se desenvuelve a la par de aquella. Apreciando el gobierno el valor de estas verdades y deseando verlas aplicadas a favor de la juventud, dispone que se establezca una academia de gimnasia en la escuela pública de esta ciudad el día 1 del que entra amas tardar, sacando del fondo de propios el

\footnotetext{
${ }^{13}$ R. de J. Santoyo, «Historia de la educación física en México», FIEP Bulletin On-Line 79 (2009): 83-91. María José Garrido Asperó, Para sanar, fortalecer. Ernesto Meneses Morales, Tendencias educativas oficiales en México, 1821-1911: La problemática de la educación mexicana en el siglo XIX $y$ principios del siglo Xx (México: Centro de Estudios Educativos. Universidad Iberoamericana, 1998), 180-185.

En España también aparece el Reglamento general de colegios de segunda enseñanza, Real Decreto 6 de noviembre de 1861, cuyo artículo 35 dice: «Ocupación frecuente será la de los ejercicios físicos en el gimnasio por edades y bajo la dirección de maestro». Colección Legislativa de España (1861), 432.
} 
valor de los instrumentos necesarios constantes en el adjunto presupuesto de 81 pesos, construyéndose aquellos anticipadamente por una comisión que nombrará el ayuntamiento y que deberá asociarse con el señor profesor en medicina y cirujía don José Ignacio de la Garza García, que va a dirigir la academia. Dígolo a V. para su cumplimiento, previniendo que en esto se obre con mucha actividad.

Dios y libertad. Julio 21 de 1853.-Pedro de Ampudia.-Santiago Vidaurri, secretario.- Sr. alcalde 1. de esta capital. ${ }^{14}$

En el Estado de Veracruz, fue el Instituto nacional de Veracruz el que en 1855 estableció los ejercicios gimnásticos para atender la educación física de la juventud, así como sucedía — decían - en las naciones de Europa, donde apenas había un colegio que no se enseñase la gimnástica. ${ }^{15}$ Con la intención de establecer una educación moderna y completa dispusieron de la creación de un gimnasio en el patio (pórtico gimnástico), encargándose de las lecciones el profesor Lucas de Castro, sub-director y catedrático de francés y contabilidad mercantil, sin percibir retribución alguna. El instituto se satisfacía pues del nuevo ramo de la educación que pronto recibirían los alumnos «con el cual van a disfrutar horas diarias de recreo y de entretenimiento, al paso que se harán fuertes y robustos con unos ejercicios, tan útiles y necesarios al desarrollo físico del hombre». ${ }^{16}$

En 1858 en la ciudad de México, Feliciano Chavarria y Hipólito Murguía abrieron una escuela de Gimnástica y Esgrima en la calle Donceles, 20, que disponía de todos los aparatos necesarios. Chavarria, que se decía era el mejor alumno de Turin, llevaba algunos años dirigiendo la enseñanza en varios colegios nacionales y particulares, y por eso «merece toda la confianza de las familias, porque durante muchos años entre sus discípulos, algunos de los cuales son de muy tierna edad, no ha ocurrido un solo accidente desgraciado». ${ }^{17}$

Más tarde, Joaquín Noreña, otro alumno de Turin, del que se decía que era el profesor de Gimnástica más influyente, y que tenía experien-

\footnotetext{
${ }^{14}$ «Estado de Nuevo León», Diario del Gobierno de la República Mexicana, 23 de agosto de $1853,2$.

15 «Departamento de Veracruz», El Universal, 18 de junio de 1855, 1.

16 «Departamento de Veracruz», El Universal, 20 de junio de 1855, 1-2.

17 «Gimnástica», El Siglo Diez y Nueve, 25 de mayo de 1858, 2.
} 
cia como tal en los colegios nacionales desde 1857, abrió en ciudad de México una "Escuela de Gimnástica» en la calle de San Francisco, 7. Se decía que era el gimnasio «más grande completo y cómodo hasta hoy visto en México». En este gimnasio, Noreña invitaba sobre todo a los niños pequeños de los colegios particulares (de seis a ocho de la mañana y de siete a diez de la noche) y exclusivamente a los niños (de cinco y media a seis y media de la tarde). El método empleado venía garantizado por una excelente reputación, puesto que ninguno de los niños había sufrido percance alguno y, además, se demostraban los excelentes resultados al restituir la salud a niños débiles y enfermos. ${ }^{18}$

En 1868, Noreña se ocupaba de dirigir la gimnástica en la Escuela Nacional Preparatoria de profesores, en la que también se impartían clases de esgrima y de ejercicios militares. Como anota María José Garrido, Noreña se ocupó de clases de gimnástica en los colegios de la ciudad, ${ }^{19}$ entre ellos la Escuela Preparatoria de la Sociedad Católica de México y el Rode's English Boarding-School. ${ }^{20}$

Por lo tanto, a través de estos pioneros fueron difundiéndose las ventajas de la enseñanza gimnástica, que además de proteger la salud y robustecer al ser humano, engrandecía el poder de los ejércitos y la independencia de las naciones libres. Así lo opinaba, en 1873, el literato y publicista español Adolfo Llanos Alcaraz, que destacaba como la gimnástica regeneraba la especie humana y sanaba las enfermedades, ${ }^{21}$ tal y como ya lo estaba demostrando, desde hacía veinte años, la celosa dirección de Noreña en su «abandonada» escuela de Gimnástica. ${ }^{22}$ Este mismo año, Llanos Alcaraz estableció un gimnasio medicinal (gimnás-

\footnotetext{
${ }^{18}$ Joaquín Noreña, «Escuela de Gimnástica», La Sociedad (Ciudad de México), 9 de septiembre de $1863,4$.

${ }^{19}$ Garrido Asperó, Para sanar, fortalecer.

20 «Rode’s English Boarding-School», El Foro (Ciudad de México), 3 de enero de 1880, 3.

${ }^{21}$ «Persuadido de la necesidad de que se generalicen en México los trabajos gimnásticos y de que terminen de una vez las absurdas preocupaciones que contra ellos existen, voy a publicar inmediatamente un Tratado especial de Gimnástica para que los padres distingan los ejercicios higiénicos médicos y ortopédicos, que curan muchas dolencias y evitan muchos padecimientos, sin exposición alguna, de los ejercicios de adorno o de maroma que, si bien pueden dar al hombre la agilidad del mono y la fuerza del gigante, encierran verdaderos peligros». Adolfo Llanos y Alcaraz, Pedrería falsa: colección de guijarros literarios. (México: Imp. «La Colonia Española» de A. Llanos, 1875). «La Gimnástica», 271-285 (p. 285).
}

${ }^{22}$ Adolfo Llanos Alcaraz, «Actualidades», Correo del Comercio (México), 9 de agosto de 1873, 1. 
tica higiénica, médica y ortopédica), llamado Alhambra Mexicana, que estuvo funcionado hasta $1879 .{ }^{23}$

En 1874 la Junta Directiva de Instrucción Pública propuso instalar gimnasios higiénicos en las escuelas primarias y los ejercicios obligatorios de gimnasia de salón. ${ }^{24}$ Sobre ello hablaba José Díaz Covarrubias, refiriéndose al vacío existente en la educación corporal que, si bien se había introducido en algunos colegios de instrucción secundaria y profesional, en las escuelas de instrucción primaria se encontraba completamente desatendida. De aquí que proponía, siguiendo lo legislado, que se incorporasen la «gimnasia higiénica» diariamente, mañana y tarde, veinte o treinta minutos con ejercicios dirigidos por los propios maestros, puesto que no hacía falta ser un hercúleo o un especialista, simplemente con la ayuda de algún manual sobre esta materia, y la de un monitor joven, había más que suficiente. Advertía por eso, que en este tipo de gimnasia no tenía lugar la ya desacreditada gimnasia atlética, por lo que «el salto mortal, las piruetas del trapecio y otros esfuerzos tan inútiles como peligrosos» quedan prohibidos. ${ }^{25}$ De aquí que, por la facilidad en la realización de los ejercicios sin aparatos, Díaz Covarrubias otorgase a este tipo de gimnasia el nombre de «autogimnasia», es decir, la llamada gimnasia de salón o de sala.

Entre las obras que mencionaba Díaz Covarrubias para la enseñanza de la gimnasia higiénica, el Manual popular de gimnasia de sala médica e higiénica del Dr. Schreber era uno de los más conocidos en toda Latinoamérica, ${ }^{26}$ y, por lo tanto, también se presentaba susceptible de servir de guía en la gimnástica escolar. ${ }^{27}$ No obstante, también había otras obras. Así, por ejemplo, en el Instituto Literario de Valladolid (Estado de Yucatan), en la asignatura de «Gimnástica» de la enseñanza Preparatoria, el profesor Manuel Rejón García utilizaba el tratado del gimna-

\footnotetext{
${ }^{23}$ Garrido Asperó, Para sanar, fortalecer.

${ }^{24}$ Sánchez Somoano, Gimnástica escolar, 26-27. José Díaz Covarruvias, La instrucción pública en México: Estado que guardan la instrucción primaria, la secundaria y la profesional (México: Imp. del Gobierno, 1875), xxxvIII.

${ }^{25}$ Díaz Covarruvias, La instrucción pública, XXXvI.

${ }^{26}$ D. G. M. Schreber, Manual popular de gimnasia de sala médica e higiénica (Madrid: Carlos Bailly Bailliere, 1861). La 4 . $^{\circ}$ edición española de 1864 se vendía en México por la Librería Madrileña, $L a$ Razón de México, 17 de febrero de 1865, 4.

${ }^{27}$ Xavier Torrebadella, «La influencia de la profesión médica en la educación física española del siglo xIX: Análisis social del Manual popular de gimnasia de sala, médica e higiénica del Dr. Schreber», Cultura, Ciencia y Deporte 9, no. 26 (2014): 163-176. http://dx.doi.org/10.12800/ccd.v9i26.434.
} 
siarca español Pedro Carlier, Gimnasia médica y civil. ${ }^{28}$ Esta obra, que estaba destinada a los profesores y directores de gimnasios para que sirviera de guía en estos establecimientos, era una mera aplicación de los ejercicios de sala del Dr. Schreber y de los ejercicios en aparatos de Amorós. ${ }^{29}$

Efectivamente, la gimnasia de sala estaba garantizando la comodidad de la enseñanza de una nueva materia que podía ser dirigida a ambos sexos. La primera obra publicada en México fue una traducción del libro del francés Eugenio Paz (1836-1901), Gimnasia de salón sin aparatos (1880); ${ }^{30}$ una traducción de Manuel Peredo que, según Chávez, fue la primera publicación de la educación física para uso de las escuelas del país. ${ }^{31}$

Posteriormente, el Congreso Higiénico-Pedagógico de 1882 reforzó la necesidad del ejercicio físico en la primera enseñanza. La 5. ${ }^{a}$ Comisión puso su atención en la educación física, ocupándose lógicamente en todo cuanto se relacionaba con mejorar las condiciones higiénicas de los locales, la disposición y el tipo de mobiliario escolar, la necesidad de disponer de patios de recreo para los juegos al aire libre y, naturalmente, la conveniencia de los ejercicios corporales. Todo concluyó con la propuesta de una escuela modelo que siguiese el método de Froebel, y una

\footnotetext{
${ }^{28}$ Manuel Rejón García, «Instituto Literario de Valladolid», La Razón del Pueblo, (Mérida, Estado de Yucatan), 21 de julio de 1879, 2. La obra utilizada era la de Pedro Carlier, Tratado de gimnasia médica y civil (Santander: Imp. de I. González, 1867). Carlier era director de los gimnasios del Ateneo Mercantil, Industrial y Recreativo y del Colegio Provincial agregado al Instituto de 2. ${ }^{a}$ enseñanza de Santander.

${ }^{29}$ Este tipo de gimnasia (de sala o de salón) estaba compuesta de ejercicios elementales: movimientos de cabeza, de brazos, de piernas, pero además Carlier incorporaba las marchas gimnásticas e introducía ejercicios elementales con implementos (mazas, pesas, etc.). En lo que respecta al método de Amorós, aparecen ejercicios en los aparatos de paralelas, argollas, trapecios, cuerdas, escaleras, barras de suspensión, etc., y, finalmente, ejercicios de saltos libres, luchas y carreras.

${ }^{30}$ «No es la gimnástica, como generalmente suele creerse, el trapecio, y nada más que el trapecio; no la constituyen únicamente las barras, las pértigas (o perchas), el trampolín y algunos otros trabajos, que en ciertas imaginaciones ignorantes o mal intencionadas, le hacen confundirse con la escuela del acróbata o del atleta.

Hay en la gimnástica un poco de todo eso; pero todavía hay mucho más.

Hay una graduación de movimientos que procede de la ciencia, y que debe ser el resultado de largos estudios y de sana experiencia; hay, por fin una, variedad inagotable de ejercicios y de actitudes, cada cual con su fin especial y calculado». Eugenio Paz, Pequeño curso de gimnasia de salón sin aparatos (México: Lib. de la Enseñanza, 1880), 92-93.

${ }^{31}$ Mónica Lizbeth Chávez González, «Representaciones del cuerpo y el género en la ejercitación física en México, siglos XIX y XX», Alter. Enfoques Críticos 1, no. 1 (2010): 29-41.
} 
educación física que alternase diferentes medios como los juegos al aire libre, los ejercicios de marcha militar, los cantos combinados con juegos gimnásticos, los coros patrióticos y recreativos, los ejercicios militares, la gimnasia de salón y, también, la gimnasia con aparatos. Para terminar, las conclusiones de esta Comisión referidas al ejercicio corporal quedaron resumidas del siguiente modo:

Los ejercicios corporales, de carácter general, que se impartirán, consistirán principalmente en los juegos al aire libre.-Se practicaran ejercicios de marcha en los tres años.-Se practicará la gimnástica de salón, en el segundo año, como auxiliar suplementario en el tercero se hará uso de aparatos, impidiendo el acrobatismo.-Se practicarán bien los ejercicios de aparato respiratorio y voz, por medio de cantos adecuados. ${ }^{32}$

Los acuerdos de este congreso tuvieron su concreción en la Ley federal de Instrucción Primaria, de 23 de mayo de 1888, impulsada por Porfirio Díaz. Al cabo de dos años, cuando esta Ley entró en vigor, se dispuso la obligatoriedad de los ejercicios gimnásticos (y de los ejercicios militares) para todos los colegios del país. ${ }^{33}$ En definitiva, el tipo de gimnasia se reducía a una rudimentaria y disciplinada gimnasia de sala (o de salón), los juegos, las marchas y los cantos, además de los ejercicios militares.

Lo mismo sucedió con la Escuela Normal de Profesores de Instrucción primaria (ENP) en la ciudad de México, perteneciente al Ministerio de Justicia y de Instrucción Pública. ${ }^{34}$ La intención de la ENP era unificar la enseñanza bajo un sistema homogéneo en todos los Estados de la República. Durante la formación de cuatro años se contemplaba la asignatura de Gimnástica en los cursos $1 .^{\circ}, 2 .^{\circ}$ y $4 .^{\circ}$, y los ejercicios militares en los cuatro cursos. ${ }^{35}$ La ENP dispuso de una escuela anexa de párvulos (niños

\footnotetext{
${ }^{32}$ Memorias del Primer Congreso Higiénico Pedagógico reunido en la ciudad de México el año de 1882 (México, Imp. del Gobierno, 1883), 170-175.

${ }^{33}$ Meneses Morales, Tendencias educativas, 425-432.

${ }^{34}$ Patricia Ducoing, «Origen de la Escuela Normal Superior de México», Revista Historia de la Educación Latinoamericana 6 (2004): 39-56. Meneses Morales, Tendencias educativas, 401-403.

${ }^{35}$ Destacan sobre esta escuela las tesis doctorales de Mónica L. Chávez González, «La introducción de la educación física en México: representaciones sobre el género y el cuerpo, 1882-1928» (Tesis de maestría en Historia, Colegio de San Luis Potosí, 2006) y Reyna Nayeli Hernández Salazar, «Las políticas educativas y la educación física de México». (Tesis doctoral Universidad Autónoma del Estado de México, Toluca, Facultad de Ciencias de la Conducta, 2015).
} 
y niñas entre 4 y 7 años), que seguía el sistema de Froebel y los «juegos gimnásticos», y otra escuela de Instrucción Primaria que incorporaba las asignaturas de «Gimnástica práctica» $\mathrm{y}$ «Ejercicios militares». ${ }^{36}$

La plantilla de la ENP preveía un profesor de Gimnástica teórica y práctica con un sueldo de 600 pesos. ${ }^{37}$ Como conocemos, esta plaza fue ocupada en febrero de 1887 por José Sánchez, ${ }^{38}$ que tuvo el honor de montar el gimnasio de la Escuela Normal y de iniciar la dirección de las clases. ${ }^{39}$ Para la enseñanza utilizó el manual de texto Gimnástica pedagógica; un reconocido tratado que este profesor había publicado en España. ${ }^{40}$

Por otro lado, es de destacar que este profesor en 1888 puso en circulación El Sport Mexicano, revista mensual de educación física y primera de su clase publicada en México. El primer número (creemos que fue el único) salió a la luz a primeros de diciembre. ${ }^{41}$ Así se ofrecía la noticia en El Escolar Mexicano:

El Sport Mexicano. Con el nombre que encabeza estas líneas ha empezado a publicarse un periódico mensual, bajo la dirección del inteligente profesor de Gimnástica, Sr. José Sánchez Somoano.

El programa del nuevo colega es trabajar porque nuestro país se presente mayor atención a la educación física de la niñez.

Muy loable nos parece el propósito, y deseamos al Sr. Sánchez completo éxito en la empresa.

Con gusto establecemos cambio. ${ }^{42}$

\footnotetext{
${ }^{36}$ Meneses Morales, Tendencias educativas, 401-403.

${ }^{37}$ «Escuela Normal de Profesores», Periódico Oficial del Estado de Coahuilla (Saltillo), 27 de diciembre de 1886, 1-2.

38 «Nombramientos», La Patria (México), 24 de febrero de 1887, 3.

${ }^{39}$ Mílada Bazant de Saldaña, Historia de la educación durante el porfiriato (México DF: El Colegio de México AC, 2006).

${ }^{40}$ José Sánchez González de Somoano, Tratado de gimnasia pedagógica para uso de las escuelas de primera y segunda enseñanza e institutos (Madrid: Imp. de Manuel Minuesa de los Ríos, 1883).

${ }^{41}$ No hemos tenido la oportunidad de consultar este número que parece haber desaparecido de los fondos documentales convencionales.

42 «El Sport Mexicano», El Escolar Mexicano, 9 de diciembre de 1888, 8.
} 
Con motivo de la exposición de París, José Sánchez mencionaba que en lo relativo a la educación, México se encontraba a la altura de los países más avanzados (Francia, Alemania, Estados Unidos...), puesto que tomaba de ellos lo mejor de cada sistema. Así, por ejemplo, no debía envidiar a nadie en educación física:

Si es en educación física, por la fotografía que aquí se ve del Gimnasio Normal de México, se puede comprender que está a la altura de los mejores de Europa y América; y en cuanto a sistema, baste decir que está patentado en los Estados Unidos, México y España.

Hace poco leímos en una revista científica de París un buen artículo, lamentándose de la mala dirección que en Francia se da a la educación física de los niños, por emplear ejercicios propios de la gimnasia atlética y militar, que de la gimnasia pedagógica.

Pues bien, en México se halla ya establecido el sistema pedagógico, y dentro de un año saldrán profesores convenientemente instruidos para extenderla hasta las escuelas de aldeas. ${ }^{43}$

La llegada de José Sánchez a México coincidió con un momento en el que se estaban debatiendo las políticas pedagógicas y los sistemas gimnásticos más convenientes para atender la educación física escolar. ${ }^{44}$ En los primeros Congresos de Instrucción Pública celebrados el primero entre $1889-1890$ y, el segundo, entre 1890 y 1891, se concretó la enseñanza de la gimnasia y de los ejercicios de instrucción militar. Así, el primer Congreso estableció que la Instrucción Primaria elemental para niños empezase a los seis años, incorporando en ésta los ejercicios militares: «Además de los ejercicios militares como medios de educación física, son indispensables los juegos al aire libre y los ejercicios gimnásticos». ${ }^{45}$

Posteriormente, llegó otra oficialización de la gimnasia en la enseñanza primaria por la Ley de Instrucción Pública de 19 de junio de 1890,

\footnotetext{
${ }^{43}$ José Sánchez Somoano, «Inauguración del Pabellón Mexicano», El Siglo Diez y Nueve, 26 de julio de $1889,1$.

44 «Sánchez Somoano», El País, 23 de enero de 1894, 2.

45 «Congreso Pedagógico», El Tiempo, 15 de marzo de 1890, 2.
} 
que declaró la obligatoriedad de los ejercicios llamados «autogimnásticos» y las excursiones mensuales, pero su falta de concreción curricular y la de un profesorado formado hizo que su desarrollo fuese irregular. ${ }^{46}$ Aun así, hubo escuelas de instrucción primaria que fueron puestas de modelo, como la Escuela «Hijos de Hidalgo» de la fábrica de Miraflores (en el Distrito de Chalco), que reunía a los hijos e hijas de los obreros. En esta escuela se destacó la ejemplaridad y la perfección de los ejercicios gimnásticos de las niñas:

En la gimnasia de salón, especialmente las niñas, tienen ejercicios verdaderamente notables. Toda esta gimnasia se hace por medio de la música, así como muchos de los movimientos de los alumnos para el cambio de clase, y entrada y salida de los departamentos. Más de sesenta niñas vimos nosotros hacer ejercicios gimnásticos, con pesas de madera de unas cuatro libras, en ocho tiempos, y con tal precisión, con tal exactitud, que aparecían movimientos automáticos hechos por cuerpos inanimados, a impulso de una máquina de vapor. Tienen también las niñas ejercicios de barra, tomados en parte de Laisné, ${ }^{47}$ y en parte puestos por la señorita María Tovar. ${ }^{48}$

En el Estado de Nuevo-León, la Dirección General de Instrucción Pública concretó su propio Programa de enseñanza para las escuelas oficiales de 2. ${ }^{\text {a }}$ Clase, cuyas asignaturas comprendían: Moral y Urbanidad, Instrucción Cívica, Lengua Nacional (lectura y escritura), Lecciones de cosas, Aritmética y sistemas métrico-decimales, Nociones de ciencias físicas y naturales, Nociones prácticas de geometría, Historia patria, Dibujo, Gimnasia y ejercicios militares (en las escuelas de niños), Labores (en las escuelas de niñas) y Canto coral (donde fuere posible). Entre los textos normativos para $1 .^{\circ}$ y $2 .^{\circ}$ año, la guía de los profesores de "Gimnasia» era el ya citado Pequeño curso de Gimnasia de Salón, sin aparatos. En cuanto a la materia de "Gimnasia y ejercicios militares», para 2..$^{\circ} \mathrm{y}$

\footnotetext{
${ }^{46}$ Arturo Gil Mendoza, «Génesis de la educación física como disciplina escolar en las escuelas primarias del Estado de México, 1890-1918», Alter. Enfoques Críticos, Deportes y Sociedad 1 (2010): 41-55. Arturo Gil Mendoza, «La enseñanza de la gimnasia sueca en las escuelas primarias de Toluca. 18901914», Revista ISCEEM 9 (2010): 31-38.

${ }^{47}$ Napoleón Laisné (1810-1896), destacado gimnasiarca francés discípulo y continuador del método de Francisco Amorós.

${ }^{48}$ E. M. de los Ríos, «Boletín del Monitor», El Monitor de la República, 3 de julio de 1890, 1.
} 
4. ${ }^{\circ}$ curso se utilizaban las Nociones tácticas de Infantería, para uso de las escuelas del estado de Nueva León, arregladas por una Comisión nombrada por el Estado. ${ }^{49}$ El programa de gimnasia y de ejercicios militares se establecía del siguiente modo (Tabla 1):

Tabla 1. Programa de gimnasia y de ejercicios militares escuelas de Instrucción Primaria del Estado de Nuevo-León (1892)

\begin{tabular}{|l|l|}
\hline \multicolumn{1}{|c|}{ Curso } & \multicolumn{1}{c|}{ Contenido de la materia } \\
\hline $1^{\circ}{ }^{\text {o }}$ & $\begin{array}{l}\text { Gimnasia para niños y niñas: Ejercicios de conjunto sin instrumentos, } \\
\text { comprendiendo movimientos de cabeza, el tronco y las extremidades. }\end{array}$ \\
\hline $2^{\circ}$ & Gimnasia para niños y niñas: Repetición de los ejercicios del año anterior. \\
\hline $3^{\circ}$ & $\begin{array}{l}\text { Gimnasia y ejercicios militares para niños: Instrucción de la escuadra sin } \\
\text { armas, en el orden cerrado; alternándose con la primera parte de los ejercicios } \\
\text { gimnásticos de agilidad. }\end{array}$ \\
$\begin{array}{l}\text { Gimnasia para niñas: Ampliación de los ejercicios de conjunto de los años } \\
\text { anteriores y juegos gimnásticos. }\end{array}$ \\
\hline $4{ }^{\circ}$ & $\begin{array}{l}\text { Gimnasia y ejercicios militares para niños: Ejercicios de la escuadra con } \\
\text { armas, en la primera mitad del año escolar; y en la segunda, ejercicios de la } \\
\text { escuadra en orden disperso. Estos ejercicios se alternarán con los } \\
\text { comprendidos en la segunda parte de los gimnásticos de agilidad. } \\
\text { Gimnasia para niñas: Repetición de los ejercicios del año anterior. }\end{array}$ \\
\hline
\end{tabular}

Hay que añadir, además, que en 1890 se creó en la capital del país el Gran Círculo Central Gimnástica Mexicana «Porfirio Díaz», que probablemente fuera la primera asociación privada de la educación física de México. Aunque no tenemos demasiados datos, conocemos que fue una iniciativa de Abelardo Carrillo Albornoz, un joven profesor de educación física de las escuelas públicas primarias, que más tarde llegaría a Inspector de esta materia. El objeto de este Círculo era de propagar en la República la gimnástica higiénica y medicinal. ${ }^{50}$

\footnotetext{
${ }^{49}$ Dirección General de Instrucción Pública, «Programa de enseñanza para las escuelas oficiales de 2. ${ }^{a}$ Clase», Boletín de Instrucción Primeria del Estado de Nuevo-León (Monterrey), 12 de febrero de $1892,1-8$.

50 «Círculo de Gimnástica Mexicana», La Patria (México), 23 de abril de 1890, 3. En dicho Círculo se encontraban importantes propagandistas de la cultura física en México: Feliciano Chevarria, Joaquín Noreña, Pedro Alfaro, Emilio Lobato, Enrique F. Martínez, Mateo Sainz, Lucio Plata, Eduardo Veraza y Agustín R. Ocampo.
} 
Para concretar el sistema de educación física escolar mexicano se presentó el Tratado elemental de gimnástica higiénica y pedagógica de Alberto de Landa. ${ }^{51}$ En este libro se desarrolla la gimnasia de salón (o la enseñanza de los ejercicios auto-gimnásticos) y los ejercicios de marchas y evoluciones de conjunto. Además, el texto fue declarado oficial para la enseñanza y recomendado, como también lo fue la Gimnasia de Salón de Eugenio Paz. ${ }^{52}$ En España la obra de Paz también fue recomendada por Eusebio Ferrer, profesor de Gimnástica del Instituto de Mahón, como un buen método de gimnasia de «sala o casera». ${ }^{53}$

En el Estado de Zacatecas, la ley de 5 de marzo de 1897 propuso para la instrucción primaria (niños y niñas de 6 a 12 años) una educación pública obligatoria, gratuita y laica. Aquí, la gimnasia en la educación elemental aparecía a diario. El primer año comprendía movimientos libres, marchas y juegos gimnásticos; el segundo año, el programa del año anterior y, además, ejercicios con bastón; el tercer año, el programa del año anterior y, además, ejercicios con mazas; y el cuarto año: alternación de los ejercicios prescritos para los años anteriores. En cuanto a las niñas, la asignatura quedaba reducida a los juegos y ejercicios gimnásticos, sin los ejercicios militares que eran substituidos por las labores de mano. Para el primer año de la enseñanza superior se prescribían los ejercicios con instrumentos y sin ellos (tres veces por semana); y para el 2. ${ }^{\circ}$ año, ejercicios con aparatos (dos veces por semana), además de los correspondientes ejercicios militares (dos veces por semana). ${ }^{54}$

Asimismo, la Ley orgánica de instrucción primaria de 15 de mayo de 1897 para el Estado de México, aunque solamente indicó la auto-gimnástica o los ejercicios calisténicos, no impidió que los ejercicios militares fueran introducidos libremente en las escuelas, ${ }^{55}$ situación que

\footnotetext{
${ }^{51}$ Alberto de Landa, Tratado elemental de gimnástica higiénica y pedagógica (México: Gallego Hermanos, 1894).

52 Joaquín E. Ortega, «La Instrucción Pública en México», El Popular ( México), 17 de agosto de 1897, 1.

${ }^{53}$ Eusebio Ferrer y Mitayna, Resumen de lecciones teóricas y prácticas de gimnástica. Curso de 1893-94 (Mahón: Imp. B. Fábregues, ca. 1894).

${ }^{54}$ Ejecutivo del Estado, Ley orgánica de instrucción primaria (Zacatecas: Tip. del Hospicio de niños de Guadalupe, 1897), 39-57.

${ }^{55}$ Arturo Gil Mendoza, Historia de la educación física en México, 1890-1915. El caso estado de México (Toluca: Biblioteca Pedagógica del Estado de México, 2008), 46. http://en.calameo.com/books/ 001013128d456e8986f4a.
} 
posteriormente fue confirmada en el Reglamento de $1898 .{ }^{56}$ En este Estado, la militarización escolar se intensificó, y a principios del siglo xx se declaró su obligatoriedad en las escuelas elementales con la asignatura de ejercicios de táctica militar. El objetivo no era otro que el de «crear un soldado ciudadano de guardia nacional, para defensa del honor y de la independencia de la República cuando fuera necesario». ${ }^{57}$ Es decir, se pretendía instruir súbditos ciudadanos, obedientes y disciplinados, con sentido del deber y respeto a la autoridad nacional. Asimismo, se añadía que

además de los ejercicios militares y como medio de educación física, son indispensables los juegos al aire libre y los ejercicios gimnásticos. Habiéndose establecido que a la edad de seis años (que) comienza la enseñanza elemental, los niños puede practicar desde entonces los ejercicios militares. ${ }^{58}$

Por lo tanto, las materias seguían las orientaciones curriculares acordadas en los congresos pedagógicos, con lo cual se daba continuación a la política nacionalizadora del porfiriato que pretendía la uniformidad educativa de todo el país. ${ }^{59}$ En este sentido, las materias de gimnasia y ejercicios militares cohesionaban el enaltecimiento patriótico y el stock del capital corporal en la construcción de un modelo de identidades individuales dispuestas a consagrar el encaje nacionalizador en una conciencia colectiva. ${ }^{60}$

La gimnástica y los ejercicios militares útiles, desde el punto de vista nacional, abastecían de ciudadanos fuertes y robustos para la defensa del Estado. Sobre esta biopolítica actuaba el mito de la Guerra Franco-Pru-

\footnotetext{
${ }^{56}$ Estado de México, Reglamento para los exámenes de las escuelas primarias oficiales del Estado de México (México: Oficina Tip. del Gobierno, 1898), 14.

${ }^{57}$ Gil Mendoza, Historia de la educación física, 46.

${ }^{58}$ Ernesto López Orendaín, «La educación física en el periodo de 1900 a 1920», en Programa de Estudios, 3er semestre, Licenciatura en Educación Física/La educación en el desarrollo histórico de México II (México, 2003), 1-16.

${ }^{59}$ Lucia Martínez Moctezuma, «Historia de la educación física en México», en La invención del 'homo gymnasticus'. Fragmentos históricos sobre la educación de los cuerpos en movimiento en Occidente, coord. Pablo A. Scharagrodsky (Buenos Aires: Prometeo, 2011), 299-320.

${ }^{60}$ María Esther Aguirre Lora, "Ciudadanos de papel, mexicanos por decreto», en Historia cultural y educación. Ensayos críticos sobre conocimiento y escolarización, comps. Thomas S. Popkewitz, Barry M. Franklin, y Miguel A. Pereyra (Barcelona: Pomares, 2003), 297-331.
} 
siana, aquella idea de que la superioridad gimnástica de los alemanes sobre los franceses decidió el triunfo de los primeros. ${ }^{61}$

Desde finales de siglo XIX, la gimnástica sueca se presentaba como la alternativa pedagógica para atender la educación física en la escuela primaria. ${ }^{62}$ De ello se hacía eco la Revista de la Instrucción Pública Mexica$n a$, cuya dirección consideró conveniente incorporar un extenso artículo del profesor chileno Joaquín Cabezas, que trataba sobre la gimnasia sueca como el mejor sistema de educación física posible. ${ }^{63}$ Efectivamente, la propaganda de la gimnasia sueca en México, como en otros países de América y Europa, se estaba extendiendo rápidamente. Al llegar a 1902 se estaban ultimando los detalles de una Academia de gimnasia para formar profesores de ambos sexos en la enseñanza, siguiendo el método de educación física sueco, muy poco conocido en el país, pero de éxito notable en Estados Unidos y Europa. ${ }^{64}$ Así que, en el mes de julio, se puso en marcha la Academia de Gimnasia de México, estableciéndose posteriormente otras academias por todo el país. ${ }^{65}$

El interés del Gobierno por la educación física escolar condujo a enviar profesorado a los Estados Unidos para estudiar los sistemas gimnásticos, especialmente el sueco. ${ }^{66}$ Posteriormente, los profesores Manuel Velázquez Andrade y Alberto de Landa también fueron en comisión de estudios al Real Instituto de Estocolmo. Este último profesor, siendo Inspector de Gimnasia de las Escuelas Nacionales, en 1903 daba a conocer la Academia de Gimnasia Sueca; ${ }^{67}$ una entidad cuya iniciativa venía de la Dirección General de Instrucción Pública que reguló las disposiciones a cumplir por todas las Academias de Gimnasia del Distrito Federal de México. Entre estas disposiciones se mencionaba utilizar «como guía el

\footnotetext{
${ }^{61}$ Rodolfo Menéndez, «Gimnástica y ejercicios militares», La Escuela Primaria (Mérida de Yucatán), 15 de julio de 1897,1 .

${ }^{62}$ Rodolfo Menéndez, «Educación física», La Escuela Primaria (Mérida de Yucatán), 1 de marzo de 1894, 184.

${ }^{63}$ Joaquín Cabezas, «Del exterior. Gimnasia sueca», Revista de la Instrucción Pública Mexicana, 7 de enero de 1896, 245-255. Joaquín Cabezas García es considerado el padre de la educación física chilena.

${ }^{64}$ "Las academias de gimnasia», El Tiempo (México), 1 de mayo de 1902, 2.

${ }^{65}$ Gil Mendoza, «La enseñanza de la gimnasia sueca», 32-33.

${ }^{66}$ "La gimnasia sueca», El Imparcial (México), 17 de octubre de 1904, 4.

${ }^{67}$ Chávez González, La introducción de la educación física, 85.
} 
tratado de Gimnástica Racional Sueca de Ch. Liedbeck, ${ }^{68}$ obra, aunque incompleta, contiene lo esencial para los niños, y cuyas deficiencias cubrirá el Inspector del ramo». ${ }^{69}$ Alberto de Landa, que ha sido considerado como el promotor de la gimnasia sueca en México, creó en 1905 la Asociación de Gimnástica Racional y Juegos al Aire Libre. ${ }^{70}$ Como ya hemos mencionado, en junio de 1906, este profesor también fue comisionado por el Ministerio de Instrucción Pública a Estocolmo para perfeccionar los estudios de la educación física, con el objeto de implantar el método sueco a su regreso, con todas las reformas necesarias y, así, adoptarlo oficialmente, ${ }^{71}$ tal y como sucedió, oficialmente en el sistema educativo. ${ }^{72}$

La evidencia que mostraba la moda de la gimnasia sueca fue la edición de la archiconocida obra de Kumlien y André, La gimnasia sueca: manual de gimnasia racional al alcance de todos y para todas las edades, ${ }^{73}$ muy conocida en toda Latinoamérica. ${ }^{74}$ Por consiguiente, la gimnasia sueca cohabitaba con los ejercicios militares y proporcionaba un perfecto acomodo a los códigos disciplinares de obediencia y sumisión, a las voces de mando y a la autoridad. ${ }^{75}$

Igualmente, el profesor Manuel Velázquez Andrade (1877-1952) desde Estocolmo remitía interesantes artículos que difundían la gimnasia sueca. ${ }^{76}$

\footnotetext{
${ }^{68}$ C. H. Liedbeck, Gymnastiska dagöfningar valda bland dem som begagnats vid Stockholms stads folkskolor under åren 1870-80 (Stockholm: Norstedt, 1881).

${ }^{69}$ "Las academias de gimnasia. Nuevas disposiciones», El Popular (México), 17 de julio de 1903, 2.

${ }^{70}$ Hernández Salazar, Las políticas educativas. López Orendaín, «La educación física», 5.

${ }^{71}$ «Gimnasia sueca», El Tiempo (México), 28 de junio de 1906, 3.

72 «Próximas oposiciones. La Gimnasia Sueca», El Mundo (México), 21 de febrero de 1906, 2.

${ }^{73}$ L. G. Kumlien y Emile André, La gimnasia sueca: manual de gimnasia racional al alcance de todos y para todas las edades (París y México: Lib. de la Vda. de C. Bouret, 1904). Esta obra tuvo ediciones en 1908, 1909, 1914 y 1918; naturalmente también fue muy conocida en España.

${ }^{74}$ Lucía Martínez Moctezuma (coord.), Formando el cuerpo del ciudadano. Aportes para una historia de la educación física en Latinoamérica (Morelos: Universidad Autónoma del estado de Morelos, Instituto del Deporte y Cultura Física del Estado de Morelos, 2016).

${ }^{75}$ En esta época en España se publican también obras en torno a la gimnasia sueca como las de Vicente Romero, Cartilla-compendio de gimnasia racional a pie firme y manos libres (Madrid: Imp. de los Hijos de M. G. Hernández, 1905) y L. G. Kumlien, La gimnasia para todos (Madrid: Librería Gutemberg de José Ruiz, ca. 1907).

${ }^{76}$ Manuel Velázquez Andrade, «Algunas de mis ideas pedagógicas sobre educación física», La Enseñanza Primaria 1 de octubre de 1905, 229-132, y «El Instituto Central de Gimnasia de Stockolmo. Breve historia acerca de su fundador Per Henrik Ling y sus sucesores», La Enseñanza Primaria, 22 de diciembre de 1905, 219-223.
} 
Al llegar de Suecia, este profesor continuó su formación en el «Instituto Posee», de Boston y, más tarde, después de otra estancia en el Real Instituto de Estocolmo y de otros viajes de estudios por Francia, Bélgica y Alemania, ${ }^{77}$ accedió a la plaza de Inspector de la Gimnasia en las Escuelas Nacionales Primarias del Distrito Federal. Por ello debe considerársele el representante más importante de la educación física mexicana de principios de siglo $\mathrm{xx} .^{78}$

Fue en las reformas educativas de Ley del 15 de agosto de 1908 cuando apareció una voluntad explícita de introducir en la cultura física inquietudes higiénicas y médicas. El currículo de educación física fue más análogo con los tiempos modernos, es decir, hacia la práctica de la gimnástica sueca y los deportes. Aunque, eso sí, continuaron los ejercicios militares configurando una parte importante del programa educativo.

La significativa contribución bibliográfica llegó con Velázquez Andrade. ${ }^{79}$ En 1908 creó y presidió la Asociación Mexicana de Educación Física, año culminante que se completó con la creación, por parte de la Secretaría de Guerra y Marina, de la Escuela Magistral de Esgrima y Gimnasia (1908-1914), cuya misión fue la de proporcionar un cuerpo de instructores para el ejército. ${ }^{80}$

En estos años la gimnasia sueca en México ya había desterrado por completo el sistema de José Sánchez y las obras que llegaban de España tenían puesta la mirada en Suecia. Así sucedía con el Manual de

\footnotetext{
77 «Triunfos de un Pensionista Mexicano en Stokolmo», El Tiempo, 6 de marzo de 1906, 2.

${ }^{78}$ Mónica Lizbeth Chávez González, «Construyendo la nación y el género desde el cuerpo: las prácticas deportivas en la historia de la educación mexicana, 1880-1930», en xxvi Congreso de la Asociación Latinoamericana de Sociología (Guadalajara: Asociación Latinoamericana de Sociología, 2007) http://www.aacademica.org/000-066/1922.

${ }^{79}$ Hay que destacar las siguientes obras de Manuel Velázquez Andrade: La educación física. Actitudes viciosas y correctas en las escuelas (México: Tipografía Económica, 1907), Manual de gimnasia educativa: obra escrita para servir de texto y guía para los maestros de las escuelas primarias de uno y otro sexo (Paris México: Lib. Vda. de C. Bouret, 1909), Las bases científicas de la educación física (México, 1908), Educación física. Primer año. Obra escrita para servir de guía a los maestros de las escuelas Primarias Elementales, y texto a los alumnos de las Escuelas Normales en sus clases de Metodología de los ejercicios físicos (México: Librería de la vda. de Ch. Bouret, 1909), Educación Física. Segundo Ano. Obra escrita para servir de guía a los maestros de las Escuelas Primarias Elementales y de texto a los alumnos de las Escuelas Normales en su clase de Metodología de los Ejercicios Físicos (México: Librería de la vda. de Ch. Bouret, 1910).

${ }^{80}$ López Orendaín, «La educación física», 8-11.
} 
gimnasia racional y práctica (método sueco), ${ }^{81}$ traducción castellana de Francisco de la Macorra Guijeño, antiguo profesor de Escuela Central de Gimnástica, y Profesor de Gimnástica en el Instituto de San Isidro de Madrid..$^{82}$

El sistema mexicano de educación física quedó expuesto en el II Congreso Nacional de Educación Primaria, en la conferencia del profesor Velázquez Andrade. Como ya realizó en el III Congreso Internacional de Higiene Escolar de París en 1910,83 Velázquez Andrade se inclinaba por una educación física con preferencia en la gimnasia sueca y los juegos corporales. En dicha educación, se marcaban las condiciones diferenciales de género de la época con ejercicios menos enérgicos, menos violentos, más estéticos y rítmicos para las jóvenes. Se trataban también los juegos deportivos al aire libre: basket-ball, foot-ball, base-ball, hockey, natación, saltos, carreras...

Velázquez Andrade arremetía todavía contra la confusión de la educación física con la gimnasia acrobática que se impartía en los establecimientos explotadores de los llamados gimnasios higiénicos. Finalmente, pedía más protección del Ministerio de Instrucción Pública y la necesaria creación de campos de juego. Terminó la conferencia advirtiendo:

El campo de juego es la medicina más eficaz de combatir los peligros de la ociosidad y la vagancia de los niños por las calles y plazas, y recordad que estas dos cosas son las más de las veces, las causas directas de la criminalidad tanto infantil como la de los adultos. ${ }^{84}$

Al llegar a 1913 el debate metodológico de los sistemas gimnásticos no cesaba y la gimnasia sueca tuvo que enfrentarse a otro sistema, que en este caso provenía del método natural del francés George Hébert (1875-

\footnotetext{
${ }^{81}$ M. Soleirol de Serves y Mme Le Roux, Manual de gimnasia racional y práctica (método sueco) (Madrid: Librería Editorial de Bailly-Balliere e Hijos, 1906).

82 «Bibliografía», El Tiempo (México), 11 de noviembre de 1908, 1.

${ }^{83}$ Manuel Velázquez Andrade, «Bases fisiológicas, sicológicas, sociológicas y pedagógicas que norman la educación física de los niños, adolescentes y adultos, de uno y otro sexo, en las escuelas del Distrito Federal de México», Anales de la Higiene Escolar 2 (1912): 132-146.

${ }^{84}$ Manuel Velázquez Andrade, Conferencia teórico-práctica sobre Educación Física dada a los delegados del 2. ${ }^{\circ}$ Congreso Nacional de Educación Primaria el sábado 30 de septiembre de 1911 en el gimnasio de la Escuela Normal Primaria para Maestros (México: Imp. de A. Carranza e hijos, 1911), 16.
} 
1957), expuesto en sus Lecciones prácticas de cultura física, ${ }^{85}$ donde se propugnaba un nuevo sistema de educación física que cuestionaba la eficacia del método sueco.

\section{APUNTE SOBRE LA EDUCACIÓN FÍSICA ESCOLAR EN ESPAÑA}

La falta de una bibliografía en torno a la educación física escolar era una constatación. ${ }^{86}$ El único libro publicado exprofeso era un sencillo y atrevido tratado de Joaquín Lladó editado en 1868, Nociones de gimnástica higiénica. ${ }^{87}$ La educación física escolar estaba en pleno abandono y la ley educativa de la época (Ley Moyano de 1857) no había contemplado su inclusión.

Fue hacia 1870 cuando se empezaron los trabajos para conquistar el logro de un Gimnasio Normal en Madrid, siendo el Diputado Emilio Castelar el que presentó a las Cortés un proyecto que pasó totalmente desapercibido. No obstante, en 1873 se logró, al menos, que una Ley de Instrucción Pública consignase la enseñanza de la gimnástica en los Institutos y Escuelas de segunda enseñanza, aun siendo de forma voluntaria, pero la inestabilidad política de entonces no hizo prosperar su enseñanza. ${ }^{88}$

No en balde, a partir de la Restauración surgieron influyentes voces del Magisterio que insistieron en enfatizar la importancia de dicha educación. En este sentido, es de destacar aquí a Pedro de Alcántara García Navarro (1842-1906), que publicó varias obras que marcaron una inflexión en la conciencia pedagógica española. ${ }^{89}$ En su Teoría y Práctica de la Enseñanza, ${ }^{90}$ Pedro de Alcántara García abordó ampliamente

\footnotetext{
${ }^{85}$ George Hébert, Lecciones prácticas de cultura física (París y México: Viuda de C. Bouret, 1913).

${ }^{86}$ Xavier Torrebadella, «Crítica a la bibliografía gimnástica de la educación física en España (18001939)", Anales de Documentación 16, no. 1 (2013): http://dx.doi.org/10.6018/analesdoc.16.1.158851.

${ }^{87}$ Joaquín Lladó, Nociones de gimnástica higiénica, aplicables a las escuelas de instrucción primaria de uno y otro sexo como elementos de educación física (Barcelona: Lib. Juan Bastinos e Hijo, 1868).

${ }^{88}$ José Sánchez Somoano: Gimnástica escolar, Juegos Calisthénicos, Biblioteca Popular de Gimnástica - tomo II (Madrid: Imp. de la Viuda de M. Minuesa de Los Ríos, 1894), 18.

${ }^{89}$ Pedro de Alcántara García, «La gimnástica en la educación primaria», Revista de la Universidad de Madrid 5, no. 5 (1875): 473-491.

${ }^{90}$ Pedro de Alcántara García, Teoría y práctica de la educación y la enseñanza. Curso completo y enciclopédico de pedagógica, expuesto conforme a un método rigurosamente didáctico, De la educación física. Tomo V (Madrid: Gras y Ci. ${ }^{a}$ Editores, 1882).
} 
el problema de la educación física. Su impacto pedagógico también fue especialmente significativo en México. ${ }^{91}$ Este mismo año coincidía con la publicación de las primeras revistas profesionales de la educación física, El Gimnasta Español (Madrid, 1882) y El Gimnasio (Madrid, 1882), las cuales ejercieron una poderosa influencia en la aprobación de la primera Ley de la educación física española y la creación de la Escuela Central de Gimnástica (ECG, 1887-1892).${ }^{92}$ El lamentable cierre de la ECG provocó el enojo del profesorado oficial de Gimnástica que, a partir de entonces, se organizó para reclamar sus derechos profesionales y la oficialización de la gimnástica escolar. ${ }^{93}$

En el entorno pedagógico, además de las avanzadas propuestas de Pedro de Alcántara García, ${ }^{94}$ por otro lado se desenvolvía el discurso regeneracionista de la Institución Libre de Enseñanza (ILE), que lideró Francisco Giner de los Ríos, en el contexto de las ideas del krausismo y del positivismo de Spencer, del que también se desenvolvía una preferencia por el estilo de enseñanza inglés, que a la sazón estimuló la puerta de entrada del deporte escolar en Madrid.

En el contexto general, la España de la Restauración se caracterizó por un crecimiento del movimiento obrero, cuyas reivindicaciones sociales chocaban con los intereses de los poderes hegemónicos (las estructuras militares, la monarquía, la burguesía liberal y conservadora, el caciquismo, las oligarquías y la Iglesia), que hacían de las políticas un usufructo personalizado, y cuya mayor fuente de beneficios se encontraba en la explotación de las colonias de ultramar. Los sucesivos gobiernos administraban una fragilidad política y económica de espaldas al

\footnotetext{
${ }^{91}$ Como apunta Gil Mendoza en Historia de la educación física, 21-26, en México se destacaba la influencia del español Pedro de Alcántara García también de esta obra.

${ }^{92}$ Xavier Torrebadella, «Las primeras revistas profesionales y científicas de la educación física española (1882-1936)», Apunts. Educación Física y Deportes 190 (2012): 11-25.

${ }^{93}$ Anastasio Martínez Navarro, «Datos para la historia de una iniciativa fallida: la Escuela Central de Gimnástica», Historia de la Educación 14-15 (1996): 125-149. Juan Andrés Cambeiro, "El proceso de institucionalización de la educación física en la España contemporánea» (Tesis doctoral no publicada, Universidad de Barcelona, Departamento de Historia y Teoría de la Educación, 1997). Xavier Torrebadella, «De la Asociación de Profesores y Profesoras Oficiales de Gimnástica (1891) al Colegio Nacional de Profesores de Educación Física (1948). Un análisis histórico para una crítica del presente. I parte (1891-1900)», Revista Española de Educación Física y Deporte 413 (2016): 79-95.

${ }^{94}$ Pedro de Alcántara García Navarro, De las teorías modernas acerca de la educación física (Madrid: Imp. de Gil y Navarro, 1886).
} 
problema de la lucha de clases. A todo esto, debe añadirse un contexto social preocupado por la depauperación de las clases subalternas, y la degeneración física que se extendía a todas las capas de la sociedad, en la que se veían unas amenazas cuya trascendencia afectaba al imaginario colectivo de los círculos higienistas y pedagógicos de la autoproclamada buena sociedad..$^{95}$

Además, hay que añadir la existencia de una formación militar infantil en la que, en complicidad con la Iglesia, los maestros y las autoridades promovían los populares batallones infantiles, cuyo único sentido era el de impulsar organizaciones patrióticas de defensa nacional, monárquica y católica como reacción al desarrollo revolucionario del movimiento obrero. ${ }^{96}$

En este orden, los apóstoles de la educación física intervinieron profundamente convencidos de que la regeneración del pueblo español debía empezar por su regeneración física; es decir, por hacer oficial y obligatoria la enseñanza de la gimnástica a todos los niveles educativos. ${ }^{97}$

Hasta entonces, la educación física puede decirse era solamente accesible, como asignatura de adorno o necesaria, en los colegios privados de la «buena sociedad». Y por lo que se refiere a la enseñanza pública, esta quedaba a expensas de la voluntad pedagógica de los maestros, y si el lugar o el espacio disponible del colegio lo permitía. La educación física en la escuela primaria no llegó legalmente hasta principios del siglo xx; aun así, fue todo un fracaso puesto que no había, ni se otorgaron, los medios necesarios para cumplir su efectividad. Esta situación fue denunciada en el Congreso de Primera Enseñanza celebrado en Barcelona en el año 1909-10. La conferencia del profesor de gimnasia sueca Víctor Langlois

\footnotetext{
${ }^{95}$ Antonio David Galera, «Educación física y protección de la infancia en la I Restauración (18751931). Regulaciones laborales e institucionales complementarias escolares», Cabás, 13 (2015): 1-37. Xavier Torrebadella, «Cuerpos abandonados y rescatados. La educación física en los orfanatos españoles del siglo XIX», Cabás, 10 (2013): 11-28.

${ }^{96}$ Xavier Torrebadella, «Los batallones infantiles en la educación física española (1890-1931)», ODEP. Revista Observatorio del Deporte 1, no. 1 (2015): 32-70.

${ }^{97}$ Xavier Torrebadella, «De la Asociación de Profesores y Profesoras Oficiales de Gimnástica (1891) al Colegio Nacional de Profesores de Educación Física (1948). Un análisis histórico para una crítica del presente. II parte (1901-1948)», Revista Española de Educación Física y Deportes 414 (2016): 85-102.
} 
du Feu trató sobre el asunto y sus conclusiones fueron aprobadas por el Congreso:

1. ${ }^{a}$ Organizar metódicamente la educación de los sentidos en las clases de párvulos y elementales.

2. ${ }^{\mathrm{a}}$ Imponer obligatoria y cotidianamente la somoscética o gimnasia racional en todos los centros docentes.

3. ampliar los estudios de los maestros con un curso de Higiene de la Educación Física.

4. ${ }^{\text {a }}$ Crear una Facultad de Educación física en las Universidades de Madrid y Barcelona.

5. ${ }^{\text {a }}$ Fomentar un cuerpo de inspectores de Educación física. ${ }^{98}$

\section{JOSÉ SÁNCHEZ Y GONZÁLEZ DE SOMOANO (1850-1913)}

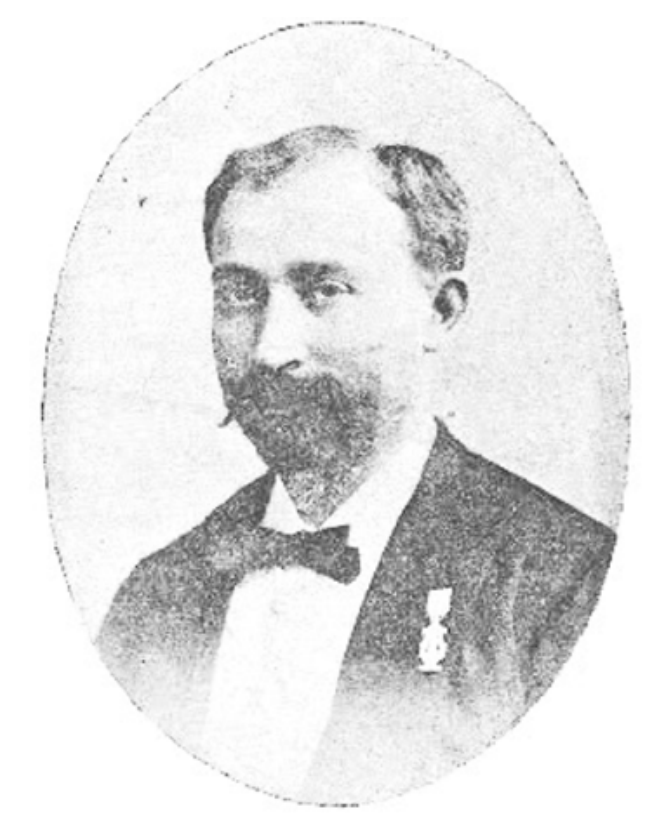

Imagen 1. José Sánchez y González de Somoano.

Fuente: Gimnástica Escolar. Tomo I (ca. 1890)

\footnotetext{
${ }_{98}$ Víctor Langlois du Feu, La educación física como base y norma de toda pedagogía racional y biológica, (Barcelona: Imp. Tasis, 1910), 4. (Tema presentado en el Congreso de Primera Enseñanza celebrado en Barcelona en el año 1909-10)
} 
José Sánchez y González de Somoano (Arriondas, 1850 - México, 1913) fue un conocido gimnasiarca y literato, miembro de la Sociedad de Escritores y Artistas Españoles, de la ILE (imagen 1), propietario y director de varios gimnasios en Madrid y autor de varias obras de gimnástica, científicas y literarias.

Se estableció en Madrid a la edad de diez años y muy pronto se dedicó a la gimnástica, siendo auxiliar en el gimnasio que el profesor Alfonso Vignolles dispuso desde 1861. Allí también aprendió con el profesor Vicente López Tamayo. Con dieciocho años, hacia 1868, José Sánchez se estableció por cuenta propia en un gimnasio de Valladolid y, luego, en otro de Santander. ${ }^{99}$ De regreso a Madrid, hacia 1873, dispuso de otro gimnasio en la c/ de las Infantas, 19 y 21. En 1876 se anunciaba en El Imparcial como Gran Gimnasio Higiénico, Médico y Ortopédico, y disponía de la dirección médica facultativa del Sr. Coll. Las clases eran para caballeros y niños, pero también las había reservadas para señoras.

Dos años más tarde, en el municipio de Valdemoro, creó y reglamentó el gimnasio modelo de la Guardia Civil para instruir a los guardias jóvenes. ${ }^{100}$

El gimnasio de la c/ de las Infantas se trasladó de la c/ Almirante, $5 .{ }^{101}$ Este gimnasio se quemó el 3 de septiembre de 1882; ${ }^{102}$ no obstante, en pocos días se hizo con el gimnasio la c/ Alcalá, 7 establecido en la Fonda Peninsular. En el nuevo gimnasio contrató los servicios de José Merelo y Casademunt, uno de los esgrimistas más destacados de España. ${ }^{103}$ En octubre dispuso también del Gran Gimnasio Higiénico en la c/ de Alcalá, 80 (al lado del Palacio del Marqués de Portugalete). ${ }^{104}$

En esta época José Sánchez se presentaba, junto a Mariano Marcos Ordax, como el fundador y director de la revista El Gimnasio, de «educa-

\footnotetext{
${ }_{99}$ Pedro Pascual Martínez, Escritores y editores en la Restauración canovista, 1875-1923. Vol. 2 (Madrid: Ediciones de la Torre, 1994), 725.

100 "Sánchez Somoano», El País, 23 de enero de 1894, 2.

101 «Gimnasio», El Imparcial, 19 de marzo de 1880, 4.

102 «El incendio de ayer», El Liberal, 4 de septiembre de 1882, p. 3

103 "Gran Gimnasio y Sala de Armas», El Liberal, 19 de septiembre de 1882, 4.

104 «Noticia generales», La Discusión, 16 de octubre de 1883, 3.
} 
ción física y de higiene», cuyo primer número se publicó el 1 de enero de 1882. Se trataba de una publicación mensual, que aparecía cada primero de mes. La publicación estaba dirigida facultativamente por Marino Marcos Ordáx y José Sánchez figuraba como director literario.

En 1883 editó un folleto de divulgación y propaganda informativa del horario y tipo de clases impartidas en el citado Gran Gimnasio Higiénico, «para caballeros y niños» y «para señoras y señoritas» que, además, contenía varios artículos con la intención de concienciar de las ventajas de la gimnasia: «A los padres de Familia. El afán de ser sabios», «Utilidad de la gimnasia»y «Método para adelgazar». ${ }^{105}$ Este mismo año, también publicó el Tratado de Gimnasia Pedagógica, ${ }^{106}$ obra que fue premiada en la Exposición Literaria de Madrid de 1884. Luego apareció Propaganda Gimnástica, que reunía un compendio de algunos de sus artículos publicados anteriormente. ${ }^{107}$

José Sánchez también se dedicaba a la venta de aparatos gimnásticos y al montaje de instalaciones de gimnasios en colegios y casas particulares. ${ }^{108}$ Además, desde 1875 comercializaba un sistema patentado de poleas, «Sistema Sánchez», cuyo «nuevo método de gimnasia racional» permitía el ejercicio físico a todas aquellas personas que no podían asistir a los gimnasios y, también conseguir grandes beneficios físicos. ${ }^{109}$

La propaganda que con este aparato hemos hecho desde la época ya citada, la dejamos a la pública consideración, pues basta decir que antes, tratándose de gimnasia, no se hablaba más que de trapecios, torniquetes, pesas y paralelas. Hoy, antes que

\footnotetext{
${ }^{105}$ José Sánchez y González de Somoano, Gran Gimnasio Higiénico (Madrid: Imp. de Manuel Minuesa de los Ríos, 1883).

${ }^{106}$ Sánchez González de Somoano, Tratado de gimnasia. Existe una tercera edición en (Biblioteca Popular Gimnástica: tomo X), Madrid: Imp. de la Viuda de M. Minuesa de los Ríos, 1894.

${ }^{107}$ José Sánchez González de Somoano, Propaganda gimnástica (Madrid: Imp. Minuesa de los Ríos, 1884). Parece ser que existen varias ediciones: edición de la Biblioteca Popular Gimnástica, tomo IX (Madrid: Imp. de la Viuda de M. Minuesa de los Ríos, 1894). José Luís Pastor Pradillo en La Educación Física en España, 635, cita otra edición en Biblioteca Popular (Madrid: Est. Tip. de Alfredo Alonso, 1892).

${ }^{108}$ Sánchez González de Somoano, Propaganda, 132.

${ }^{109}$ José Sánchez y González de Somoano, Nuevo método de Gimnástica racional con la polea sistema Sánchez con patente de invención por veinte años (Madrid: Imprenta de Manuel Minuesa de los Ríos, 1886).
} 
todo esto, se habla de poleas, y nadie encontraría completo un gimnasio que careciese de ellas. Éste es el resultado de nuestra propaganda, hecha teórica y prácticamente. ${ }^{110}$

En agosto de 1886 se embarcó para estudiar el desarrollo de la educación física en el extranjero, puesto que había recibido un encargo del Gobierno español para la redacción del Reglamento y Programas de la futura Escuela Central de Gimnástica. ${ }^{111}$ Parece ser que renunció a la Cátedra vitalicia que se le ofreció como profesor en la ECG. ${ }^{112}$ Aún así, mientras José Sánchez permaneció en Madrid durante los años 1889 a 1892, no entendemos la razón que le impidió presentarse como alumno libre para acceder a la titulación de profesor de Gimnástica en la ECG.

José Sánchez encarnaba el perfil del liberal republicano y era muy crítico con la política educativa de la Restauración, de aquí su relación con la ILE. ${ }^{113}$ Su partida a México, un país emergente y próspero, le otorgaba la posibilidad de rehacerse en nuevos proyectos. Se comentó que no volvería a España hasta que no estuvieran instaladas las escuelas de profesores y profesoras de gimnástica. ${ }^{114}$ José Sánchez era un hombre comprometido con el movimiento regeneracionista español y creía profundamente que, a través de la regeneración física y moral, la juventud española tenía una oportunidad para superar la actual situación de decadencia. Pero era también un culto literato que experimentaba en la poesía, la novela y el ensayo. Entre sus obras destacan: Versos trasnochados (1884), Gimnástica intelectual (Madrid, 1884), Ensayos literarios (Madrid, 1885), México a vista de pájaro (Madrid, 1890), Modismos, locuciones y términos mexicanos (Madrid, 1892), Costumbres yankees. Viajando por América del Norte (México, 1894), El Ciego (México, 1895), El banco de piedra (México, 1898) y El pájaro sin nido (México, 1912). ${ }^{115}$ Colaboró

\footnotetext{
${ }^{110}$ Sánchez González de Somoano, Nuevo método de Gimnástica, 3-4.

${ }^{111}$ Pueden verse los reglamentos de la ECG en Jose Sánchez Somoano, Gimnástica escolar, Juegos Calisthénicos, Biblioteca Popular de Gimnástica -t. II- (Madrid: Imp. de la Viuda de M. Minuesa de Los Ríos, 1894), 15-39.

112 «Sánchez Somoano», El País, 23 de enero de 1894, 2.

113 José S. González de Somoano, «La educación física en España», La Época, 4 de agosto de $1879,3$.

${ }^{114}$ Felipe Serrate, «Hemos tenido el gusto...», La Ilustración Gimnástica, 15 de agosto de 1886, 93.

115 Pascual Martínez, Editores y escritores, 752.
} 
también como articulista y literato en numerosos periódicos de la época, tanto en España como en México.

A mediados de septiembre de 1886 José Sánchez llegó a la ciudad de México con la intención expresa de montar un gimnasio, asunto del que daba noticia la prensa. ${ }^{116}$ Muy pronto presentó allí, en la Secretaría de Fomento, el aparato de «Polea Sistema Sánchez», para el desarrollo físico de ambos sexos. ${ }^{117}$ Durante su primera estancia en la metrópoli mexicana se encargó de instalar y tutelar varios gimnasios. Conocemos que en enero de 1887 había ubicado su domicilio en la c/ San Francisco, 1, en donde también había dispuesto un Gimnasio Médico y comercializaba (al precio de 40 pesos) el «Nuevo método de gimnasia racional» por medio de la polea "Sistema Sánchez». ${ }^{118}$ En diciembre de 1888 estableció otro Gimnasio Médico, en la c/ cerrada de Jesús, en cuyo local también se encontraba la redacción de El Sport Mexicano, pero con tan mala suerte que sufrió un robo, con la desaparición de la ropa de gimnástica, cinturones, juegos de pesas, lámparas y otros enseres. ${ }^{119}$ Pero como ya hemos dicho, José Sánchez no dejó los negocios de Madrid, y en marzo de 1887 se volvía abrir, tras el incendio, el gimnasio de la c/ Almirante, 5, también conocido como Gimnasio Peninsular. ${ }^{120}$ No obstante, toda su atención se concentraba en México capital donde se consagró como director del Gimnasio de la ENP, fue profesor del presidente de la República Mexicana D. Porfirio Díaz y fundador-director de El Sport Mexicano. ${ }^{121}$ Véase como se relataba lo acontecido en la revista mejicana, España y América:

[...] presentando al Señor Ministro de Justicia e Instrucción Pública un proyecto para la fundación de un Gimnasio Normal en ocasión en que se estaban haciendo los trabajos para la fundación de la Escuela Normal del distrito Federal.

\footnotetext{
116 «El Sr. José Sánchez Somoano», El Monitor Republicano (México), 19 de septiembre de 1886, 3.

117 «Solicitud», El Siglo Diez y Nueve (México), 30 de noviembre de 1886, 3.

118 «Nuevo método de gimnasia racional», El Tiempo (México), 1 de enero de 1887, 2.

119 «Robo», El Monitor Republicano (México), 14 de diciembre de 1888, 2. Reproduce una biografía de José Sánchez publicada en la revista España y América.

120 «Cartera de Madrid», El Liberal, 30 de marzo de 1887, 3.

${ }^{121}$ Sánchez Somoano, Gimnástica escolar, 19-27.
} 
Pareciéndole bien dicho proyecto al señor Ministro, y se habilitó en el nuevo edificio de la Escuela Normal un espacioso local para la instalación del Gimnasio, siendo entonces nombrado el Sr. Sánchez Somoano Director de las clases de gimnástica de dicho centro.

Cúpole después el alto honor de ser llamado por el Presidente de la República, General Porfirio Díaz para que diese clases con arreglo a su nuevo sistema de gimnástica, del que tiene privilegio exclusivo en Méjico, Estados Unidos y España. ${ }^{122}$

La acreditación de José Sánchez de servir como profesor de Gimnástica al presidente de la República, le llevó al mismo tiempo a serlo de las mejores familias de la alta sociedad mejicana y también de la comunidad española.

En 1889 regresó a Europa y asistió en junio a la Exposición Universal de París, desde donde mandaba crónicas a México. ${ }^{123}$ Luego se quedó en Madrid para ocuparse de los gimnasios que aún tenía en propiedad y atender algunos proyectos editoriales, ${ }^{124}$ entre ellos la ampliación del tratado de Gimnástica pedagógica, que pasó a formar parte de una Biblioteca Popular Gimnástica. El primer ejemplar de esta Biblioteca, Gimnasia escolar, publicado en 1890, fue dedicado a la República de México. ${ }^{125}$ De este modo, ofrecía La Época la llegada del perito profesor: «Después de una excursión de tres años, dedicada a estudiar los distintos sistemas de gimnástica en las principales naciones de Europa y América, ha regresado a esta capital el Sr. Sánchez Somoano, director del Gimnasio de la calle de Alcalá, 7 ».126

En 1892 realizó un tour por los Estados Unidos y, a raíz del viaje, publicó un libro Costumbres yankees, que también dedicó al General Porfirio Díaz. De esta obra adelantó algunos artículos en la prensa; ${ }^{127}$ uno de

\footnotetext{
122 «Sánchez Somoano», El País, 23 de enero de 1894, 2.

${ }^{123}$ José Sánchez Somoano, «Inauguración del Pabellón Mexicano», El Siglo Diez y Nueve, 26 de julio de $1889,1$.

${ }^{124}$ José Sánchez Somoano, Modismos, locuciones y términos mexicanos (Madrid: Manuel Minuesa de los Ríos, 1892).

125 Sánchez Somoano, Gimnástica escolar, 26-27.

126 «Noticias generales», La Época, 14 de noviembre de 1889, 3.

127 José Sánchez Somoano, Costumbres yankees: viajes por la América del Norte (Madrid: Tip. de El Correo Español, 1894).
} 
ellos trata sobre la Universidad de Harvard y relata el magnífico gimnasio que disponían los estudiantes. ${ }^{128}$

En 1893, en España, José Sánchez cerró el antiguo gimnasio de la c/ Alcalá, 7, y recibió el traspaso del gimnasio de la c/ Carbón, 9, con lo cual, se hizo cargo de dos gimnasios, puesto que mantenía el de la c/ Almirante, 7. ${ }^{129}$ Este mismo año regresó a México y se encargó durante un corto tiempo de la dirección de El Correo Español (segunda época).

En 1896 retornó otra vez a Madrid y aceptó la dirección del completísimo Gimnasio Higiénico médico de los Baños Árabes (propiedad Benito Díaz, c/ de Velázquez, 23, esquina con la de Goya, en el barrio de Salamanca). Un lujoso local que estaba destinado tanto para mejorar el desarrollo físico, como para corregir las deformidades del cuerpo mediante ejercicios bien combinados y dirigidos. ${ }^{130}$

En 1900 el gimnasio de la c/ Almirante, 5 continuaba funcionando y se anunciaba en la prensa la «Polea Sánchez. Aparato gimnástico de probada utilidad», pero en la misma página se anunciaba también otra «Polea higiénica. Se adquieren vigorosas fuerzas y desarrollo general y del pecho en pocos días con la nueva polea de pesas gradual, tan solicitada, sencilla y portátil». ${ }^{131}$

Siguiendo sueltos y noticias varias de la prensa de México, conocemos que, en junio de 1900, José Sánchez contrajo matrimonio en la ciudad de Guatemala con Juana Simonson, y posteriormente se instaló en Ciudad de México. No tenemos constancia de que regentase ningún es-

\footnotetext{
128 José Sánchez Somoano, «Notas Yankées», El País, 4 de septiembre de 1892, 1.

${ }^{129}$ En El Imparcial, 19 de febrero de 1893, leemos una nota que dice: «GIMNASIO. Habiéndose cerrado el de la calle Alcalá, seguirán dándose clases en los gimnasios de la calle Carbón, 9 y del Almirante, 5»

${ }^{130}$ José Díaz-Benito, Guía del Madrileño en los Baños Árabes: calle de Velázquez, número 29 (Barrio de Salamanca) (Madrid: Imprenta y Fundición de Manuel Tello, 1887). Lola Esteban Lario, Los Baños Árabes. Bibliografía del doctor Díaz-Benito y Angulo en el Madrid del siglo XIX (Nambroca: Ayuntamiento de Nambroca, 2005).

131 «Anuncios», El Imparcial, 1 de julio de 1900, 4. La «Polea Sánchez» continuó anunciándose en el Imparcial hasta 1908 y su propietario continuaba siendo José Sánchez, que contaba con la ayuda del profesor oficial de Gimnástica Juan Murillas, que también se encargaba desde 1907 del Gimnasio Modelo, c/ Santa Brígida, 4, ocupándose de la dirección del Gimnasio Peninsular de la c/ Almirante, después de la muerte de José Sánchez. Juan Murillas era también profesor de gimnástica de S. A. R. el Infante Don Alfonso y, además, instructor del Cuerpo de Bomberos de Madrid. «Los bomberos y la gimnasia», Mundo Gráfico, 17 de diciembre de 1913, 25.
} 
tablecimiento gimnástico, pero sí de la publicación de algunos artículos literarios en la prensa. Conocemos que desde 1904 formaba parte de la Junta Directiva de la Sociedad Española de Beneficencia de México, y que, en 1906, ejerció en esta Sociedad la función de secretario, sufriendo en los últimos días, antes de su muerte, una cierta situación incómoda debido a la gestión económica. ${ }^{132}$

José Sánchez murió asesinado en México, el 9 de febrero de 1913, en los sucesos iniciales de la Decena Trágica, el levantamiento militar del contrarrevolucionario General Manuel Mondragón para destituir de la presidencia de México al liberal socialista, Francisco Ignacio Madero. ${ }^{133}$

\section{La contribución bibliográfica a la educación física: «la gimnasia pedagógica»}

Destacar la contribución bibliográfica de José Sánchez en torno a la gimnástica tiene un valor añadido en un momento en que prácticamente en España no existían obras de este género y, todavía menos, escritas por autores españoles. Su primera publicación fue el ya mencionado Tratado de gimnasia pedagógica, que el mismo autor consideró ser la primera publicación realizada en España. Este manual de 279 páginas ilustrado con figuras de ejercicios —el más extenso hasta la fecha- fue presentado para servir de guía docente en las clases de gimnástica de la primera y segunda enseñanza. El estímulo para publicar esta obra venía precedido por la iniciativa gubernamental de la Ley 9 de marzo de 1883, en la que se declaró oficial la enseñanza de la gimnástica en España, situación que se presentaba favorable para emprender una empresa editorial, cuyas ventas podían ser substancialmente importantes. En una nota bibliográfica sobre esta obra se aprovechaba para mencionar que la educación física en España se encontraba en «el más criminal abandono respecto de tan importante materia, tan esmeradamente atendida en todos los pueblos cultos, así de Europa, como de América». ${ }^{134}$ Con

\footnotetext{
${ }^{132}$ Un español, «El asunto de la beneficencia española. Al Sr. Somoano», El Correo Español, 6 de febrero, 9.

133 «Hasta las 3 A. M. del día de hoy...», El Imparcial (México), 10 de febrero de 1913, 1.

${ }^{134}$ S. L. M. «Bibliografía», La Discusión, 21 de marzo de 1884, 3.
} 
lo cual, José Sánchez declaraba que, ante la carencia de métodos de gimnasia pedagógica para atender la primera y segunda enseñanza, se había marcado la «empresa de publicar el presente trabajo, teniendo en cuenta los adelantos modernos alcanzados en las principales naciones de Europa y América». ${ }^{135}$

La obra incorporó conocimientos teóricos y prácticos. Coincidimos con Pastor Pradillo que delata la «inopia conceptual» de la época, ${ }^{136}$ es decir, la escasa o nula fundamentación técnica y pedagógica. En los contenidos teóricos se ofrece un apartado de historia de los tiempos antiguos (Grecia y Roma) y otro de los tiempos modernos, analizando la gimnástica en los países de Alemania, Francia, Bélgica, Italia, Inglaterra, Estados Unidos, Portugal y España: «La educación física se halla, pues, en España muy postergada, y, considerada oficialmente, hasta ahora puede decirse que ha sido nula». ${ }^{137}$

Asimismo, se tratan muy someramente aspectos de anatomía, fisiología e higiene. La parte práctica consiste en la llamada "gimnasia de sala», para niños y niñas, de tres a seis años, y consta de la realización de ejercicios a manos libres: movimientos de cabeza, brazos, cintura y piernas. Para el alumnado de siete a doce años se marca la gimnasia con aparatos: picas, escala horizontal, trampolín, pesos cortos, pesos largos y mazas. Los ejercicios de marchas acompañadas de canto también son incluidos en el programa escolar.

José Sánchez criticaba las aplicaciones pedagógicas de la gimnástica que se venían realizando hasta la fecha, puesto que se solía emplear el mismo sistema para los niños que para las niñas: «El plan que hemos propuesto difiere en mucho de los que generalmente se siguen en la actualidad, porque en éstos suele emplearse el mismo sistema para los niños y señoritas que para los adultos». ${ }^{138}$

La parte práctica era una mera representación del conocidísimo $M a$ nual popular de gimnasia de sala del Dr. Schreber, que desde hacía años

\footnotetext{
135 Sánchez de Somoano, Tratado de gimnasia pedagógica, 7.

${ }^{136}$ José Luis Pastor, Educación física y libros de texto en la primera enseñanza (1883-1978) (Madrid: Editorial Dykinson, 2005), 132.

${ }^{137}$ Sánchez de Somoano, Tratado de gimnasia pedagógica, 51.

${ }^{138}$ Sánchez de Somoano, Tratado de gimnasia pedagógica, 8.
} 
recomendaba José Sánchez. ${ }^{139}$ Este tipo de gimnasia, dirigida a los párvulos, venía a representar todo un dispositivo de sujeción de la corporalidad infantil. Se trataba de una gimnasia completamente antinatural, cuyo método estaba concebido para inculcar la obediencia, utilizando el movimiento artificial y descompuesto del cuerpo, mediante la ejercitación y la corrección, ordenando y disciplinando toda la acción. La enseñanza (pedagógica) de la gimnástica proseguía, en la instrucción primaria, con los ejercicios de fuerza: de suspensión del cuerpo, del levantamiento de pesas y de la movilidad de las mazas. Para los niños, de doce años en adelante, además de los ejercicios anteriores, ya podían emplearse los ejercicios en las barras paralelas, pero no para las niñas, puesto que estos ejercicios, que robustecían la fuerza de los brazos, «dejan estéril su pecho y las hacen perder las formas redondas, adquiriendo las mismas que el hombre». ${ }^{140}$

En el libro aparece un capítulo, el XIII, dedicado a la esgrima de palo; compuesto de veinte lecciones, pretendía iniciar e instruir a los alumnos (a partir de los diez años) en el manejo de las armas. ${ }^{141}$ Este capítulo estaba en sintonía con el ambiente de la época y con las demandas de una gimnástica premilitar en el entorno escolar como así sucedía, por ejemplo, en Francia, país que había adoptado la organización de los batallones infantiles. Véase como José Sánchez justificaba el aludido capítulo:

Hubo un tiempo en España en que el ejercicio de las armas era el más noble y el más apreciado de todos [...]. No podía ser un buen caballero quien no supiese manejar la espada.

Pero hay un arma mucho más española todavía, que se emplea para la defensa personal en algunas de nuestras provincias del Norte, y que, sabiendo manejarla bien, facilita en extremo la esgrima del sable, que es la que parece va predominando en

\footnotetext{
${ }^{139}$ Sánchez de Somoano, «La educación física en España», La Guirnalda, 20 de agosto de 1879, 1-2. ${ }^{140}$ Sánchez de Somoano, Tratado de gimnasia pedagógica, 171.

${ }^{141}$ Años más tarde, el Inspector de Educación Física, Manuel Velázquez Andrade rechazaba decididamente la enseñanza de la esgrima en la educación física escolar y añadía que: «Como medio de cultura física, ya lo vimos, no responde a las necesidades y requisitos fisiológicos de un método racional de gimnasia». Manuel Velázquez Andrade, «La esgrima de sable y florete como medio de educación física y gimnástica. Enseñanza sin finalidad», La Enseñanza Primaria (México), 15 de marzo de 1907, 281-284.
} 
nuestros días, puesto que los desafíos por lo general todos se llevan a cabo con esta arma.

Esta esgrima es el palo; y como hay facilidad de aprenderla en todas partes y además es un buen ejercicio gimnástico, la recomendamos para uso de las escuelas de segunda enseñanza.

[...] Este y no otro es el objetivo que nos hemos propuesto, para que de esta manera se vaya desarrollando en la juventud la afición al manejo de las armas como todos los demás ejercicios corporales. ${ }^{142}$

En esta obra la influencia de Amorós y de Jahn es destacada. Aun así, José Sánchez criticó el método de Amorós, sosteniendo que estaba fundamentado en la gimnasia militar, sin una base técnica o preparatoria adecuada, que solamente se centraba en los peligrosos y forzados ejercicios de suspensión (principalmente aplicada en el trapecio, la barra fija, cuerdas y las anillas):

Hoy los métodos de Amorós y Jahn representados por el trapecio y la barra fija, son los que se disputan la primacía, debiendo desaparecer los dos en un tiempo no lejano para dar lugar a otro, cuyo autor es el sentido común, y con el cual se consigue, además de lo que pretendían dichos autores, con relación a lo militar, un buen desarrollo, que es garantía segura para todos en el porvenir. ${ }^{143}$

La influencia de Amorós venía marcada especialmente por la orientación militar, de la que José Sánchez tampoco rechazó del todo, aspecto que se revela en el sistema de ejercicios gimnásticos acompañados del canto. Nos referimos a las marchas o al paso gimnástico (con los manos en la cintura y los codos mirando hacia atrás) con cantos, y también transportando pesos cortos o largos (el fusil), evolucionando progresivamente del paso a la carrera, pero conservando siempre el orden y la precisión del paso.

\footnotetext{
${ }^{142}$ Sánchez de Somoano, Tratado de gimnasia pedagógica, 206-249.

${ }^{143}$ Sánchez de Somoano, Tratado de gimnasia pedagógica, 38-39.
} 
MOVIMIENTOS DEL TRONCO

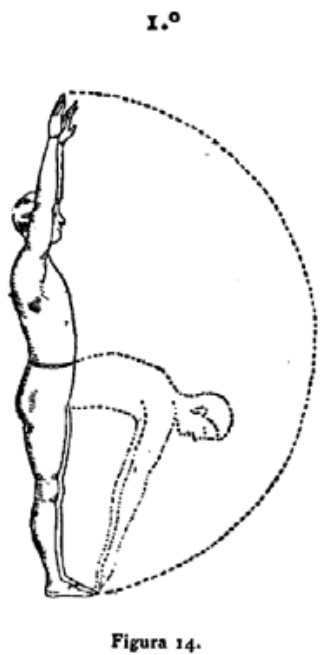

Imagen 2. Gimnástica Escolar. Tomo I (ca. 1890), 69

\section{JUEGOS VARIOS}

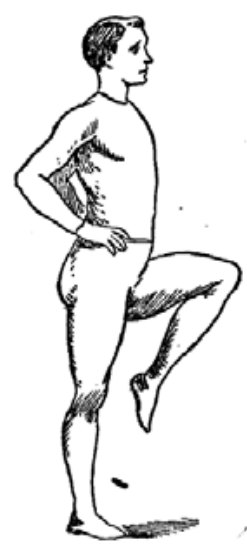

Figura 25.

Imagen 3. Gimnástica Escolar. Tomo I (ca. 1890), 91

Asimismo, José Sánchez se mostraba conforme al método ecléctico que se estaba siguiendo en los Estados Unidos:

Es la joven y próspera Nación, que se ha propuesto oscurecer a las de la vieja y caduca Europa, y que todo aquello que se propone lo consigue por su constancia y fe en el trabajo, es hoy una de las más adelantadas en Gimnasia pedagógica, pues en la mayor parte de los Estados la tienen establecida en las escuelas. ${ }^{144}$

Sobre este tratado se escribieron algunas notas críticas. En la Gaceta de Instrucción Primaria de Lérida se citaba que era excelente libro para la enseñanza pedagógica de la gimnástica, que venía a cubrir el vacío existente sobre la materia:

\footnotetext{
${ }^{144}$ Sánchez de Somoano, Tratado de gimnasia pedagógica, 47.
} 
Dos o tres tratados de gimnástica se han publicado desde entonces hasta ahora. En nuestro sentir ninguno llena tan por completo las exigencias del programa ni responde acertadamente a las necesidades pedagógicas, como el del Sr. Sánchez Somoano. [...] El Sr. Somoano ha escrito indudablemente un buen libro, siendo nuestro mayor deseo que su ejemplo sea imitado por otros para ver si de este modo se desarrolla en España el gusto hacia los ejercicios físicos en conformidad con lo que en otras naciones más adelantadas sucede. ${ }^{145}$

La obra de José Sánchez respondía adecuadamente a las conclusiones del Congreso Higiénico-Pedagógico de 1882 y, además, tanto el método como las opiniones del autor eran críticas hacia los métodos atléticos y que hacían gala de los acrobatismos, sin reparar en los peligrosos de la ya comentada gimnástica de aparatos. En esta época, las tendencias del acrobatismo gimnástico fueron dejando paso a métodos más racionales e higiénicos. ${ }^{146}$

Aún y compartiendo la tesis de José Luis Pastor, ${ }^{147}$ efectivamente podemos considerar que la obra de José Sánchez dio una substancial compresión y aplicación de la educación física escolar, aportando la primera publicación que atendió la gimnástica a partir de la posibilidad legislativa de implantar la oficialidad de dicha enseñanza. Asimismo, la obra llegó al otro lado del Atlántico y la prensa mexicana la valoró en las siguientes palabras: «Muy útil esta obrita, sobre todo en México, donde a la educación gimnástica no se le ha dado la importancia que merece». ${ }^{148}$ De esta obra se mencionaba que podía encontrarse como texto en la mayoría de las escuelas de la América española. ${ }^{149}$

\footnotetext{
${ }^{145}$ R., «La gimnástica en España», Gaceta de Instrucción Primaria de Lérida 413 (1884): 38.

${ }^{146}$ Miguel Vicente-Pedraz y Mari Paz Brozas-Polo, «El triunfo de la regularidad: gimnasia higiénica contra acrobacia en la configuración física escolar en la segunda mitad del siglo XIX», Revista Brasilera do Sporte (2015) http://dx.doi.org/10.1016/j.rbce.2015.10.006

147 «La obra es un ejemplo típico de la bibliografía de la época que, fundamentalmente, se convertía en una suerte de instrumento recopilatorio cuya finalidad más parecía buscar una excusa para su venta que la potenciación de la docencia». Pastor, Educación física, 131.

148 «Boletín Bibliográfico», El Tiempo, (México), 7 de octubre de 1886, 1.

149 «Sánchez Somoano», El País, 23 de enero de 1894, 2.
} 


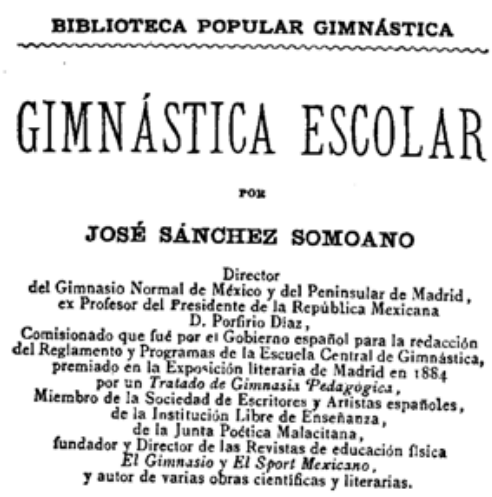

томо ।

MOVIMIENTOS LIBRES

MADRID

MANURL MINUKSA DE LOS Rtos, MEPREsoR

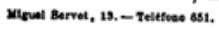

Imagen 4. Gimnástica Escolar. Tomo I (ca. 1890). Ejemplar dedicado a México.

Propaganda gimnástica es una obra de interesante valor documental en la que José Sánchez reunió diversas participaciones y discusiones parlamentarias en el Congreso de Diputados sobre la oficialidad de la gimnástica. ${ }^{150} \mathrm{El}$ resto de la obra contiene varios artículos de opinión: "La unión hace la fuerza», "Nuestro ideal», "Utilidad de la gimnasia», «El afán de hacer sabios», «La gimnasia en el bello sexo», «Bibliografías», «El gimnasio por dentro», «Método para adelgazar», «La esgrima» $\mathrm{y}$ "La equitación». Estos artículos fueron publicados en 1882 en la revista El Gimnasio y, también, en la prensa de México. ${ }^{151}$ En esta

\footnotetext{
${ }^{150}$ Proposición de Ley, del Sr. Becerra, declarando oficial la enseñanza de la gimnástica (sesión de 17 de noviembre de 1881), Discurso del Sr. Becerra en apoyo de la proposición de Ley, Contestación del Sr. Ministro de Fomento, Rectificación del Sr. Becerra y Ley de 1883 creando la Escuela Central de Gimnástica.

${ }^{151}$ Sánchez de Somoano, «El afán de hacer sabios», El Municipio Libre (México), 5 de octubre de $1886,2$.
} 
obra debemos resaltar el testimonio de José Sánchez que percibía el momento histórico de la educación física en España como «un período de luchas». Con esta expresión se refería al desinterés que existía por parte de los gobernantes, en reconocer los grandes provechos que poseía la gimnástica para el desarrollo y perfección física del bienestar de las sociedades:

Estamos en un período de luchas [...] Ahora sólo falta que el Gobierno deseche ciertos temores, y acabe de una vez haciéndola obligatoria (La Gimnástica), estando, como debe de estar, convencido de que la educación física debe anteponerse a la intelectual; pues no creemos que puedan formarse ciudadanos útiles a su patria si antes no se forman los hombres que han de ser ciudadanos. ${ }^{152}$

José Sánchez, acompañado de otros colegas de profesión (propietarios y directores "gimnasios higiénicos»), articuló iniciativas propagandísticas para difundir las ventajas y utilidades que suministraba una gimnástica bien dirigida. Con ello, también trataba de desacreditar a los meros profesores (aficionados de la gimnástica artística de o de circo), que confundían a las gentes mostrándoles una imagen equivocada de la gimnástica. Por eso, José Sánchez luchó también contra la intrusión profesional de aquellos que se empleaban sin conocimiento:

Si todos los profesores de gimnasia aunásemos nuestros esfuerzos y procurásemos, cada cual en la medida de sus fuerzas, desterrar la mucha preocupación que aun existe respecto a esta profesión, culpa en parte del público y en parte nuestra por no acabar de una vez de desterrar de los gimnasios que aun nos quedan de la llamada gimnasia artística o de circo; [...] entonces habríamos dado un gran paso para el logro de nuestras aspiraciones. ${ }^{153}$

En España este problema se desenvolvió durante varias décadas; de aquí que los profesores titulados oficialmente de Gimnástica se mostra-

\footnotetext{
152 Sánchez González de Somoano, Propaganda, «Nuestro ideal», 55-59.

153 Sánchez González de Somoano, Propaganda, 47-53.
} 
sen muy enojados por los atropellos de la profesión y el desinterés de unos gobiernos que ni hacían leyes, ni hacían cumplir las pocas que habían legislado. ${ }^{154}$

En 1890 apareció el primer volumen de la Biblioteca Popular de Gimnástica, Gimnasia escolar, el cual, como ya hemos mencionado, estuvo dedicado a México. Esta biblioteca era una substancial ampliación del Tratado de gimnasia pedagógica, que además facilitaba, por la claridad de las instrucciones y las ilustraciones «a cualquier persona en aptitud de dirigir sin otra preparación los ejercicios gimnásticos comprendidos en la Gimnástica escolar». ${ }^{155}$

Al dar a luz este libro, que viene a ser la segunda edición del Tratado de gimnasia pedagógica al que el público dispensó tan buena acogida, nos proponemos mejorarla, aumentándola considerablemente; y como la extensión ha de ser grande, la publicamos en varios tomos, facilitando al mismo tiempo su adquisición.

Cada tomo de esta Biblioteca irá precedido de apuntes históricos de la Gimnástica en distintas naciones y de algún retrato de los propagandistas más notables de Europa y América. ${ }^{156}$

A este primer tomo le siguieron otros seis, publicados entre $1890 \mathrm{y}$ 1895. La Biblioteca Popular de Gimnástica, ${ }^{157}$ en la parte dedicada a la Gimnástica Escolar, reunía cinco tomos: Movimientos libres, Juegos

\footnotetext{
${ }^{154}$ Xavier Torrebadella, «De la Asociación de Profesores y Profesoras Oficiales de Gimnástica (1891) al Colegio Nacional de Profesores de Educación Física (1948). Un análisis histórico para una crítica del presente. I parte (1891-1900)».

155 «Libros nuevos», La Época, 5 de diciembre de 1890, 4.

156 José Sánchez González de Somoano, Biblioteca Popular Gimnástica. Tomo I. Gimnasia escolar. Movimientos libres (Madrid: Imp. Vda. Minuesa de los Ríos, Biblioteca Popular de Gimnástica, ca. 1890), 11.

${ }^{157}$ Pudiera ser que esta extensa obra fuese la segunda edición de la que José Luís Pastor Pradillo cita publicada en 1892, por la Imp. Manuel Minuesa de los Ríos. También pudiera tratarse de la 2. ${ }^{\text {a }}$ edición del Tratado de gimnasia pedagógica de 1883. Lo cierto es que con las obras de este autor se confunden las ediciones con las reimpresiones, por lo que resulta difícil precisar la correspondiente edición de cada tratado, más aún cuando se tratan por tomos separados. José Luis Pastor Pradillo, La Educación Física en España: fuentes y bibliografía básicas (Alcalá de Henares: Servició de Publicaciones de la Universidad de Alcalá, 1995), 634-635.
} 
Calisthémicos, Juegos de mazas, Juegos de Picas y Juegos de Pesas ${ }^{158}$. Además, también incorporó dos tomos de Gimnasia general: Paralelas y Poleas. ${ }^{159}$ Con esta obra José Sánchez amplió el alcance social de la gimnástica y simplificó los ejercicios para un mejor uso:

Todo el que tenga algún conocimiento práctico de los ejercicios gimnásticos, podrá comprender las indudables ventajas de los que con pesos pequeños se ejecutan, porque sin esfuerzo ninguno y por la variedad de los mismos, el desarrollo llega a ser lo más igual y armónico posible.

Lo que hacía falta era un libro en el que estuviese el contenido un regular número de ejercicios, y el que hoy presentamos al público viene a llenar este vacío con treinta grabados y cincuenta combinaciones.

Hoy que la gimnasia tiende a simplificarse haciendo el mayor número de movimientos con el menor número de aparatos, creemos prestar un servicio a todos en general con la publicación por esta Biblioteca de la serie de tomitos que da comienzo con el de Movimientos libres y que termina con el Tratado de Gimnasia pedagógica.

Para las Escuelas e Institutos donde los ejercicios con aparatos se hacen poco o menos que imposibles por la gran aglomeración de alumnos, los ejercicios con pesas pequeñas, tal como los ordenamos en este libro, vienen a ser de imprescindible necesidad.

De estos libritos, hay dos sin instrumentos ni aparatos, cuatro con instrumentos y cuatro con aparatos.

\footnotetext{
${ }^{158}$ José Sánchez González de Somoano, Biblioteca Popular Gimnástica. Tomo II: Gimnasia escolar, juegos calisthémicos (Madrid: Imp. Vda. Minuesa de los Ríos, Biblioteca Popular de Gimnástica, 1894), Biblioteca Popular Gimnástica. Tomo III: Gimnasia escolar. Juegos de mazas (Madrid: Imp. Vda. Minuesa de los Ríos, Biblioteca Popular de Gimnástica, 1894), Biblioteca Popular Gimnástica. Tomo IV: Gimnasia escolar. Juegos de picas (Madrid: Imp. Vda. Minuesa de los Ríos, Biblioteca Popular de Gimnástica, 1894) y Biblioteca Popular Gimnástica. Tomo V: Gimnasia escolar y doméstica. Juegos de pesas (Madrid: Imp. Vda. Minuesa de los Ríos, Biblioteca Popular de Gimnástica, 1895).

${ }^{159}$ José Sánchez González de Somoano, Biblioteca Popular Gimnástica. Tomo VI: Gimnasia general. Paralelas (Madrid: Imp. Vda. Minuesa de los Ríos, Biblioteca Popular de Gimnástica, 1895) y Biblioteca Popular Gimnástica. Tomo VII: Gimnasia general. Gimnasia doméstica. Poleas (Madrid: Imp. Vda. Minuesa de los Ríos, Biblioteca Popular de Gimnástica, 1895).
} 
De la utilidad de todos estos libros, podrá juzgar el público cuando haya puesto en práctica su contenido y visto sus sorprendentes resultados, que es muy poco lo que se hacen esperar cuando se trabaja con verdadera perseverancia. ${ }^{160}$

\section{CONCLUSIONES}

En los estudios sobre la historia de la educación física en México, la figura de José Sánchez pasa casi desapercibida sin apenas protagonismo. Pensamos que la incorporación de José Sánchez como profesor de la Escuela Normal fue debida a la necesidad del montaje y la organización del Gimnasio, su acreditación profesional era indiscutible y la experiencia que tenía en instalar gimnasios en España le hacían acreedor de su profesionalidad. Asimismo, en aquella época, debía ser el único que en México dispusiera de una dilatada experiencia gimnasiarca y, además, de una autorizada reputación al ser nombrado por el Gobierno de España como uno de los expertos para la redacción del Reglamento y Programa de la Escuela Central de Gimnástica.

Por otro lado, llama la atención la exaltación y fidelidad de José Sánchez al presidente Porfirio Díaz, del cual además fue profesor personal de gimnástica. En este sentido, creemos que José Sánchez se aseguró la confianza del presidente, puesto que de él también dependían sus otros quehaceres profesionales en México.

Por otro lado, la ENP se presentaba como un importante eje vertebrador de política centralizadora y unificadora que trataba de sembrar la dictadura de Porfirio Díaz por todo el país. Y, como sucedía en Europa, la educación física escolar se presentaba como un dispositivo más para irradiar la conciencia colectiva de la «invención» del Estado-nación. En este campo, la República de México, a través de José Sánchez, quiso presentar un sistema genuino de educación física que no copiara a ningún sistema en concreto, y que sustentase la construcción de una identidad nacional colectiva.

\footnotetext{
${ }^{160}$ José Sánchez González de Somoano, Biblioteca Popular Gimnástica. Tomo V. Gimnasia escolar y doméstica. Juegos de pesas (Madrid: Imp. Vda. Minuesa de los Ríos, Biblioteca Popular de Gimnástica, 1895), 6 .
} 
Después de repasar la historia de la educación física escolar en México, no cabe duda de que la figura de José Sánchez fue el primer engranaje hacia la modernización pedagógica de la educación física en el periodo porfiriato. Su aportación académica, aunque breve y poco reconocida, abrió el camino para que otros continuaran la tarea de estructurar la educación física. Los sucesores, profesores mexicanos, Alberto de Landa y Manuel Vázquez Andrade son dignos ejemplos de la continuidad de un sistema de educación física cuyo principal sentido era el de engrandecer y cohesionar un emergente Estado-nación en el Nuevo Mundo.

Este sistema de educación física, que tomó como propia la gimnasia de sala (o autogimnasia) y los ejercicios militares, actuó sobre la dominación de las conciencias y ejerció de dispositivo al servicio de un poder que deseaba construir una ciudadanía disciplinada, obediente, sacrificada e ilusionada con la República de México. Se trataba pues, de una gimnasia que ejercitaba y disciplinaba; un eufemismo que, bajo el nombre de gimnasia pedagógica, utilizaba también los ejercicios con mazas y palanquetas, proporcionando a los niños la fuerza necesaria para manejar el fusil, aceptar los ejercicios de orden, las marchas y las formaciones al compás del canto patriótico (y del tambor y la corneta), y, todo ello, obedeciendo a las voces de mando. En definitiva, se trataba de una gimnasia pedagógica que no era nada más que el encauzamiento hacia la obediencia militar, la entrega total del cuerpo a las órdenes superiores, para responder en el trabajo o en la defensa de la patria.

Hacia finales del siglo xIx, la Republica de México tenía que nacionalizarse, expresión que también quería decir masculinizar y fortificar la raza para engrandecer y defender la nación de los enemigos. Tras la aceptación de la gimnasia sueca, o más tarde con el método de natural de Hébert o el deporte, da igual el método que fuera, siempre subyacía el mismo objetivo, utilizar la educación física para protegerse con los más «fuertes» (o más «frágiles») de la «invención» liberal de la República mexicana.

Finalmente, hemos determinado que la figura de José Sánchez no ha sido lo suficientemente reconocida por la literatura histórica de la educación física mexicana y española. Por lo tanto, pensamos que tiene el peso suficiente para emprender estudios de mayor envergadura, que completen su biografía y realcen su trayectoria y contribución profesional en ambos países. 
Tabla 2. Cuadro comparativo similitudes institucionales en la configuración de la educación física en México y España (1846-1913)

\begin{tabular}{|c|c|c|}
\hline Año & Acontecimiento México & Acontecimiento España \\
\hline 1845 & $\begin{array}{l}\text { Aparece la gimnasia en el Colegio } \\
\text { Gimnasio Mexicano }\end{array}$ & $\begin{array}{l}\text { 1841: Aparece la gimnasia en algunos } \\
\text { colegios privados de Sevilla, Madrid y } \\
\text { Barcelona. }\end{array}$ \\
\hline 1846 & $\begin{array}{l}\text { Primeros gimnasios privados. Jean Turin } \\
\text { alumno de Francisco Amorós }\end{array}$ & $\begin{array}{l}\text { 1840/1845: Primeros gimnasios } \\
\text { privados Víctor Venitien (Sevilla), } \\
\text { Francisco Aguilera (Madrid), José } \\
\text { María Aparici (Guadalajara), Carlos } \\
\text { Berthier (Barcelona) }\end{array}$ \\
\hline 1850 & Reglamento Gimnástica militar & 1852: Reglamento Gimnástica militar \\
\hline 1861 & $\begin{array}{l}\text { Normativa de Instrucción Pública que } \\
\text { impulsa la reglamentación de la } \\
\text { gimnástica en los colegios (15 de abril de } \\
\text { 1861) }\end{array}$ & $\begin{array}{l}\text { 1861: Normativa de Instrucción } \\
\text { Pública que impulsa la reglamentación } \\
\text { de la gimnástica en los colegios (Real } \\
\text { Decreto } 6 \text { de noviembre de 1861) }\end{array}$ \\
\hline 1873 & $\begin{array}{l}\text { Gimnasio higiénico de Adolfo Llanos } \\
\text { Alcaraz }\end{array}$ & $\begin{array}{l}\text { 1860: Gimnasio Joaquín Ramis en } \\
\text { Barcelona } \\
\text { 1861: Gimnasio Vignolles en Madrid }\end{array}$ \\
\hline 1880 & $\begin{array}{l}\text { Traducción de la obra de Eugenio Paz } \\
\text { Gimnasia de Salón }\end{array}$ & $\begin{array}{l}\text { 1861: Traducción del Manual popular } \\
\text { de gimnasia de sala, del Dr. Schreber }\end{array}$ \\
\hline 1882 & $\begin{array}{l}\text { Congreso Higiénico-Pedagógico de ciudad } \\
\text { de México }\end{array}$ & $\begin{array}{l}\text { 1882: I Congreso Nacional Pedagógico } \\
\text { en Madrid }\end{array}$ \\
\hline 1887 & $\begin{array}{l}\text { Primera revista de la educación física: } E l \\
\text { Sport Mexicano }\end{array}$ & $\begin{array}{l}\text { 1882: Primeras revistas de la educación } \\
\text { física: El Gimnasio y El Gimnasta } \\
\text { Español }\end{array}$ \\
\hline 1887 & $\begin{array}{l}\text { Gimnasio Escuela Normal de Profesores } \\
\text { de Instrucción primaria }\end{array}$ & $\begin{array}{l}\text { 1887: Escuela Central de Gimnástica } \\
(1887-1992)\end{array}$ \\
\hline 1888 & $\begin{array}{l}\text { Oficialización de la enseñanza gimnástica } \\
\text { (educación física): Ley federal de } \\
\text { Instrucción primaria de } 23 \text { de mayo de } \\
\text { 1888. Entra en vigor en } 1890 \text {. }\end{array}$ & $\begin{array}{l}\text { 1892: Primeras cátedras de Educación } \\
\text { Física } \\
\text { 1901: Oficialización de la educación } \\
\text { física en la Instrucción Primaria }\end{array}$ \\
\hline 1889 & Primer Congreso Pedagógico & $\begin{array}{l}\text { 1892: Congreso Pedagógico Hispano- } \\
\text { Portugués-Americano (Madrid) }\end{array}$ \\
\hline 1890 & $\begin{array}{l}\text { Gran Círculo Central Gimnástica } \\
\text { Mexicana «Porfirio Díaz» }\end{array}$ & $\begin{array}{l}\text { 1887: Sociedad Gimnástica Española } \\
\text { (Madrid) }\end{array}$ \\
\hline 1894 & $\begin{array}{l}\text { Alberto de Landa: Tratado elemental de } \\
\text { gimnástica higiénica y pedagógica }\end{array}$ & $\begin{array}{l}\text { 1868: Nociones de gimnástica higiénica } \\
\text { de Joaquín Lladó. } \\
\text { 1883: Gimnástica pedagógica de José } \\
\text { Sánchez. }\end{array}$ \\
\hline
\end{tabular}




\begin{tabular}{|l|l|l|}
\hline \multicolumn{1}{|c|}{ Año } & \multicolumn{1}{|c|}{ Acontecimiento México } & \multicolumn{1}{c|}{ Acontecimiento España } \\
\hline 1904 & $\begin{array}{l}\text { Kumlien y André, La gimnasia sueca: } \\
\text { manual de gimnasia racional al alcance de } \\
\text { todos y para todas las edades }\end{array}$ & $\begin{array}{l}\text { 1905: Vicente Romero, Cartilla- } \\
\text { compendio de gimnasia racional a pie } \\
\text { firme y manos libres. } \\
\text { 1907: L. G. Kumlien, La gimnasia para } \\
\text { todos }\end{array}$ \\
\hline 1908 & $\begin{array}{l}\text { Escuela Magistral de Esgrima y Gimnasia } \\
\text { (1908-1914) }\end{array}$ & $\begin{array}{l}\text { 1911: Institucionalización de la } \\
\text { gimnasia sueca en el Ejército. } \\
1919: \text { Escuela Central de Gimnasia } \\
\text { (1919-1936) }\end{array}$ \\
\hline 1908 & Asociación Mexicana de Educación Física & $\begin{array}{l}\text { 1911: Institución Española de } \\
\text { Educación Física }\end{array}$ \\
\hline 1911 & $\begin{array}{l}\text { 2. }{ }^{\circ} \text { Congreso Nacional de Educación } \\
\text { Primaria }\end{array}$ & $\begin{array}{l}\text { 1910: Congreso de Primera Enseñanza } \\
\text { (Barcelona) }\end{array}$ \\
\hline 1913 & Divulgación del método natural de Hébert & $\begin{array}{l}\text { 1913: Divulgación del método natural } \\
\text { de Hébert }\end{array}$ \\
\hline
\end{tabular}

\section{Nota sobre el autor}

XaVier Torrebadella Flix [http://orcid.org/0000-0002-1922-6785] es Licenciado en Educación Física por la Universidad de Barcelona (1991) y Doctor por la Universidad de Lérida (2009). Profesor en el Instituto Centro de Alto Rendimiento Deportivo de Sant Cugat del Vallès (CAR) y en el Departamento de Didáctica de la Expresión Musical, Plástica y Corporal de la Universidad Autónoma de Barcelona. Actualmente investiga en torno a la Historia Social y Documental de la Educación Física y el Deporte en España entre 1800 a 1939. Miembro de NEOLCYT: Grupo de Investigación en Lengua de la Ciencia y de la Técnica (siglos XVIII-XIX), Universidad Autónoma de Barcelona. Miembro del Grupo de Investigación en Pensamiento Pedagógico y Social (GREPPS) de la Universidad de Barcelona. Entre sus publicaciones destacan: Repertorio bibliográfico inédito de la educación física y el deporte en España, 1800-1939 (Madrid: Fundación Universitaria Española, 2011) y Gimnástica y educación física en la sociedad española de la primera mitad del siglo XIX (Lleida: Universidad de Lleida, 2013). 


\section{REFERENCIAS}

Aguirre Lora, María Esther. "Ciudadanos de papel, mexicanos por decreto». En Historia cultural y educación. Ensayos críticos sobre conocimiento y escolarización, editado por Thomas S. Popkewitz, Barry M. Franklin, y Miguel A. Pereyra, 297-331. Barcelona: Pomares, 2003.

Bazant de Saldaña, Mílada. Historia de la educación durante el porfiriato. México DF: El Colegio de México AC, 2006.

CAmbeiro, Juan Andrés. «El proceso de institucionalización de la educación física en la España contemporánea». PhD diss., Universidad de Barcelona, Departamento de Historia y Teoría de la Educación, 1997.

Chávez González, Mónica Lizbeth. «La introducción de la educación física en México: representaciones sobre el género y el cuerpo, 1882-1928». PhD diss., Colegio de San Luis Potosí, 2006.

- «Representaciones del cuerpo y el género en la ejercitación física en México, siglos XIX y XX». Alter. Enfoques Críticos 1, no. 1 (2010): 29-41.

- Construyendo la nación y el género desde el cuerpo: las prácticas deportivas en la historia de la educación mexicana, 1880-1930. En xxvi Congreso de la Asociación Latinoamericana de Sociología. Guadalajara: Asociación Latinoamericana de Sociología, 2007. http://www.aacademica.org/000-066/1922

Ducoing, Patricia. "Origen de la Escuela Normal Superior de México». Revista Historia de la Educación Latinoamericana 6 (2004): 39-56.

Esteban Lario, Lola. Los Baños Árabes. Bibliografía del doctor Díaz-Benito y Angulo en el Madrid del siglo XIX. Nambroca: Ayuntamiento de Nambroca, 2005.

GaLERA, Antonio David. «Educación física y protección de la infancia en la I Restauración (1875-1931). Regulaciones laborales e institucionales complementarias escolares». Cabás 13 (2015): 1-37.

Garrido AsPeró, María José. Para sanar, fortalecer y embellecer los cuerpos. Historia de la gimnasia en la ciudad de México, 1824-1876. México: Instituto Mora, 2016.

Gil Mendoza, Arturo. "Génesis de la educación física como disciplina escolar en las escuelas primarias del Estado de México, 1890-1918». Alter. Enfoques Críticos, Deportes y Sociedad 1 (2010): 41-55.

- «La enseñanza de la gimnasia sueca en las escuelas primarias de Toluca. 1890- 1914». Revista ISCEEM 9 (2010): 31-38.

- Historia de la educación física en México, 1890-1915. El caso estado de México. Toluca: Biblioteca Pedagógica del Estado de México, 2008. http://en.calameo.com/books/001013128d456e8986f4a

HeRnández SALAZAR, Reyna Nayeli. «Las políticas educativas y la educación física de México». PhD diss., Universidad Autónoma del Estado de México, Toluca, Facultad de Ciencias de la Conducta, 2015. 
López Orendaín, Ernesto. «La educación física en el periodo de 1900 a 1920». En Programa de Estudios, 3er semestre, Licenciatura en Educación Física / La educación en el desarrollo histórico de México II, 1-16. México, 2003.

Martínez Moctezuma, Lucía (coord.). Formando el cuerpo del ciudadano. Aportes para una historia de la educación física en Latinoamérica. Morelos: Universidad Autónoma del Estado de Morelos, Instituto del Deporte y Cultura Física del Estado de Morelos, 2016.

- «Historia de la educación física en México». En La invención del «homo gymnasticus». Fragmentos históricos sobre la educación de los cuerpos en movimiento en Occidente, editado por Pablo A. Scharagrodsky, 299-320. Buenos Aires: Prometeo, 2011.

Martínez Navarro, Anastasio. «Datos para la historia de una iniciativa fallida: la Escuela Central de Gimnástica». Historia de la Educación 14-15 (1996): 125-149.

Meneses Morales, Ernesto. Tendencias educativas oficiales en México, 1821-1911: La problemática de la educación mexicana en el siglo XIX y principios del siglo XX. México: Centro de Estudios Educativos. Universidad Iberoamericana, 1998. Pascual, Pedro. Escritores y editores en la Restauración canovista, 1875-1923. Vol. 2. Madrid: Ediciones de la Torre, 1994.

Pastor Pradillo, José Luis. La Educación Física en España: fuentes y bibliografía básicas. Alcalá de Henares: Servició de Publicaciones de la Universidad de Alcalá, 1995.

Pastor Pradillo, José Luis. Educación física y libros de texto en la primera enseñanza (1883-1978). Madrid: Editorial Dykinson, 2005.

Torrebadella, Xavier. «Crítica a la bibliografía gimnástica de la educación física en España (1800-1939)». Anales de Documentación 16, no.1 (2013): http:// dx.doi.org/10.6018/analesdoc.16.1.158851.

- "Cuerpos abandonados y rescatados. La educación física en los orfanatos españoles del siglo XIX». Cabás 10 (2013): 11-28.

— «De la Asociación de Profesores y Profesoras Oficiales de Gimnástica (1891) al Colegio Nacional de Profesores de Educación Física (1948). Un análisis histórico para una crítica del presente. I parte (1891-1900)». Revista Española de Educación Física y Deportes 413 (2016): 79-95.

- «De la Asociación de Profesores y Profesoras Oficiales de Gimnástica (1891) al Colegio Nacional de Profesores de Educación Física (1948). Un análisis histórico para una crítica del presente. II parte (1901-1948)». Revista Española de Educación Física y Deportes 414 (2016): 85-102.

- «La influencia de la profesión médica en la educación física española del siglo XIX: Análisis social del Manual popular de gimnasia de sala, médica e higiénica del Dr. Schreber». Cultura, Ciencia y Deporte 9, no. 26 (2014): 163176. http://dx.doi.org/10.12800/ccd.v9i26.434 
- «Las primeras revistas profesionales y científicas de la educación física española (1882-1936)». Apunts. Educación Física y Deportes 190 (2012): 11-25.

- «Los apóstoles de la educación física. Trece semblanzas profesionales en la educación física española contemporánea». Revista Española de Educación Física 406 (2014): 57-76.

- «Los batallones infantiles en la educación física española (1890-1931)». ODEP. Revista Observatorio del Deporte 1, no.1 (2015): 32-70.

Vicente-Pedraz, Miguel y Mari Paz Brozas-Polo. «El triunfo de la regularidad: gimnasia higiénica contra acrobacia en la configuración física escolar en la segunda mitad del siglo XIX». Revista Brasilera do Sporte (2015): http://dx.doi. org/10.1016/j.rbce.2015.10.006. 